\title{
Higher eukaryote-specific APC/C composition is a determinant of spindle assembly
}

\section{checkpoint importance}

Thomas Wild ${ }^{1, \#}$, Magda Budzowska ${ }^{1,2, \#}$, Gopal Karemore ${ }^{3}$, Chunaram Choudhary ${ }^{1, *}$

${ }^{1}$ Proteomics program, the Novo Nordisk Foundation Center for Protein Research, Faculty of Health and Medical Sciences, University of Copenhagen, Blegdamsvej 3B, DK-2200 Copenhagen, Denmark

${ }^{3}$ Center for Chromosome Stability (CCS), Faculty of Health and Medical Sciences, University of Copenhagen, Blegdamsvej 3B, DK-2200 Copenhagen, Denmark

${ }^{3}$ Protein Imaging Platform, the Novo Nordisk Foundation Center for Protein Research, Faculty of Health and Medical Sciences, University of Copenhagen, Blegdamsvej 3B, DK-2200 Copenhagen, Denmark

"These authors contributed equally to this work.

*Correspondence should be addressed to: chuna.choudhary@cpr.ku.dk

Key words: APC/C, mitosis, mass spectrometry, synthetic viability, MAD2, APC7, APC16, MPS1

One sentence summary: APC7 and APC16 contribute to SAC importance

\section{Abstract}

The multisubunit ubiquitin ligase APC/C (anaphase promoting complex/cyclosome) is essential for mitosis by promoting timely degradation of cyclin B1. Proper timing of APC/C activation is regulated by the spindle assembly checkpoint (SAC), which is initiated by the kinase MPS1 and implemented by MAD2-dependent inhibition of the APC/C. Here we analysed the contribution of the higher eukaryote-specific APC/C subunits APC7 and APC16 to APC/C composition, function and regulation. APC16 is required for APC7 assembly into the $A P C / C$, while APC16 assembles independently of APC7. $\triangle \mathrm{APC7}$ and $\triangle \mathrm{APC16}$ cells display no major defects in mitotic progression, cyclin B1 degradation or SAC response. Strikingly, however, deletion of either APC7 or APC16 is sufficient to provide synthetic viability to MAD2 deletion. $\triangle A P C 7 \triangle M A D 2$ cells display an accelerated mitosis and require SAC-independent MPS1 function for maintaining their genome stability. Overall, these results show how human APC/C composition critically influences the cellular fate upon loss of SAC activity. 


\section{Introduction}

Eukaryotic cells depend on the activity of the anaphase promoting complex / cyclosome (APC/C), a multi-subunit ubiquitin ligase, to progress through mitosis (Peters 2006, Pines 2011, Primorac and Musacchio 2013). Among a variety of mitotic APC/C substrates, securin and CCNB1 are the only essential APC/C substrates for mitotic progression in yeast (Thornton and Toczyski 2003). The $A P C / C$ requires the co-activator CDC20 as well as an E2 enzyme, UBE2C or UBE2D, to initiate CCNB1 ubiquitylation (Hershko et al. 1994, Yu et al. 1996, Townsley et al. 1997, Wild et al. 2016). Substrate-conjugated ubiquitin chains can be elongated by the APC/C with the E2 enzyme UBE2S, enhancing substrate degradation efficiency (Garnett et al. 2009, Williamson et al. 2009, Wu et al. 2010, Meyer and Rape 2014, Min et al. 2015). Lowering APC/C activity delays mitotic progression, whereas loss of APC/C activity is lethal.

The timing of APC/C-initiated securin and CCNB1 degradation is of critical importance for the faithful segregation of chromosomes. Proper timing is achieved by the spindle assembly checkpoint (SAC), which coordinates bipolar chromosome attachment to the mitotic spindle with APC/C-mediated securin and CCNB1 ubiquitylation (London and Biggins 2014, Sivakumar and Gorbsky 2015). The SAC is activated by the recruitment of the kinase MPS1 to unattached kinetochores. Subsequent MPS1-catalyzed phosphorylation events recruit SAC proteins to unattached kinetochores, resulting in the formation of the mitotic checkpoint complex (MCC), consisting of MAD2, CDC20, BUBR1 and BUB3 (Sudakin et al. 2001). MCC binding to the APC/C blocks substrate recognition by CDC20 and hampers access of UBE2C to initiate substrate ubiquitylation (Alfieri et al. 2016, Yamaguchi et al. 2016). While SAC function is conserved from yeast to human, its activity apparently gained importance in higher eukaryotes: deletion of SAC proteins such as MAD2 is compatible with viability in yeast, yet leads to genomic instability in mice and human cells incompatible with life (Dobles et al. 2000, Michel et al 2001, Michel et al. 2004, Meraldi et al. 2004, Kops et al. 2005).

The APC/C consists of 19 subunits composed of 14 distinct proteins. Initial low resolution structures divided the global APC/C architecture into 'platform' and 'arc lamp' (also known as 'TPR lobe') (Dube et al. 2005). Recently, the atomic architecture of APC/C has been elucidated by cryo-electron microscopy (Chang et al. 2015). The two largest APC/C subunits, APC1 and APC2, form the core of the platform, while the TPR subunits APC3, APC6, APC7 and APC8 constitute the majority of the 'arc lamp'. The catalytic center of the APC/C is formed by APC11 and APC2 along with $\mathrm{APC} 10$ and the co-activator $\mathrm{CDC} 20$ or $\mathrm{CDH} 1$ for substrate recognition. APC/C composition is conserved from yeast to human, except for two higher-eukaryote specific subunits, APC7 and APC16, located at the tip of the 'arc lamp' (Kops et al. 2010, Hubner et al. 2010, Hutchins et al. 2010, Ohta et al. 2011, Green et al. 2011, Herzog et al. 2009, Chang et al. 2015). APC7 is present in two copies and together with one APC16 molecule sits on top of APC3. Depletion experiments revealed a role of APC16 in mitotic progression and APC/C substrate stability, but not APC/C assembly (Kops et al. 2010, Shakes et al. 2011). Depletion of APC7 by RNAi in Drosophila melanogaster had limited impact on mitotic progression and, consistently, an APC7-null strain is viable (Pal et al. 2007). In vitro, it has been shown that APC3 forms a complex with APC7, and that this complex is stabilized by APC16 (Yamaguchi et al. 2015). Based on this data, the authors suggested that the APC3/APC7/APC16 subcomplex may constitute an assembly unit or that APC16 
recruits APC7 onto APC3. Here we set out to analyse the contribution of APC7 and APC16 to APC/C assembly, function and regulation using genetic knockouts in human cells.

\section{Results}

\section{$A P C 16$ is required for $A P C 7$ assembly into the $A P C / C$ in vivo}

To study the impact of APC7 and APC16 on the composition of APC/C in vivo, we fused mCherry to the $\mathrm{C}$-terminus of APC 8 and investigated $A P C / C$ composition by affinity-purification mass spectrometry (AP-MS) (Poser et al. 2008). Because APC8 is essential for cell viability, biallelic tagging of the gene indicated functional integrity of APC8-mCherry-tagged APC/C. Next, we deleted APC7 or APC16 in the APC8-mCherry cell line (Figure S1A, Figure S1B) and analysed APC/C composition with SILAC-based quantitative AP-MS (Figure $1 \mathrm{~A}$ ). We purified the APC/C from wildtype and $\triangle \mathrm{APC7}$ cells by APC8-mCherry affinity purification and compared the relative enrichment of APC/C subunits in the APC8-mCherry pulldowns over a mock pulldown. In wild-type cells, all APC/C subunits detected in the mass spectrometry analysis were enriched ( $>2$-fold) from APC8mCherry tagged cells compared to control (Figure 1B), demonstrating proper incorporation of APC8-mCherry into APC/C complexes. All APC/C subunits, except for APC7, co-purify with APC8mCherry from $\triangle A P C 7$ cells, showing that the remaining $A P C / C$ subunits assemble in absence of APC7 (Figure 1B). We confirmed APC/C assembly in cells lacking APC7 by immunoblotting using antibodies for several APC/C subunits (Figure $1 C$ ). To analyse the role of APC16 in APC/C assembly, we used SILAC-based AP-MS to compare the APC/C composition in APC8-mCherry expressing wildtype and $\triangle$ APC16 cells. Interestingly, APC/C enriched from $\triangle A P C 16$ cells not only lacked APC16, but also APC7 (Figure 1D, Figure S1C). To test whether expression of APC16 in $\triangle$ APC16 cells restores APC7 incorporation into the APC/C, we expressed APC16-EGFP in $\triangle A P C 16$ cells and analysed $A P C / C$ composition (Figure 1E). Consistent with its integration into the APC/C (Kops et al. 2010), APC16-EGFP co-purified with APC8-mCherry and, indeed, restored APC7 co-purification with APC8-mCherry. Together, these results show that in vivo APC16 incorporates into the APC/C in the absence of APC7, whereas APC7 requires APC16 for incorporation into the APC/C.

\section{Cells lacking either APC7 or APC16 display no major defects in mitotic APC/C function}

To analyse mitotic progression in cells lacking APC7 or APC16, we endogenously tagged histone $\mathrm{H} 2 \mathrm{~B}$ with mVenus and CCNB1 with mCerulean3 in wild-type, $\triangle \mathrm{APC} 7$ and $\triangle \mathrm{APC} 16$ background (Figure S2A, Figure S2B and Figure S2C) and used these cell lines to monitor mitotic timing by timelapse microscopy. Analysis of mitotic timing (defined as the timing from nuclear CCNB1 influx to anaphase onset) revealed no significant difference between wild-type, $\triangle A P C 7$ and $\triangle A P C 16$ cells (Figure 2A, Figure S2C). Concordantly, analysis of mitotic CCNB1 degradation revealed no significant alteration in CCNB1 degradation kinetics in APC7 or APC16 knockout cells (Figure 2B). Next, we assessed the responsiveness of $\triangle A P C 7$ and $\triangle A P C 16$ cells to SAC activation. Cells were treated with nocodazole, which activates the SAC, for 18 hours and the cellular DNA content was subsequently analysed by flow cytometry (FACS) (Figure S2D). Nocodazole treatment caused a marked increase of $4 N$ DNA containing cells for all analysed cell lines, showing that $\triangle A P C 7$ and $\triangle \mathrm{APC} 16$ cells remain sensitive to SAC signaling. To further verify SAC functionality in $\triangle \mathrm{APC7}$ cells, 
we analysed the nocodazole-dependent association of SAC-generated MCC with the APC/C. For both wild-type and $\triangle A P C 7$ cells an increased enrichment of the SAC proteins - BUB3, BUBR1, CDC20 and MAD2 - was observed in APC8-mCherry pulldowns upon a nocodazole-induced mitotic arrest (Figure 2C and Figure 2D). To analyse the dependence of $\triangle A P C 7$ and $\triangle A P C 16$ cells on SAC function for genomic stability, we treated cell lines with the MPS1 inhibitor reversine and subsequently analysed cellular ploidy by FACS (Figure S2E). Reversine treatment resulted in an increased number of polyploid cells ( $>4 N$ DNA content) for wild-type, $\triangle A P C 7$ and $\triangle$ AP16 cells, demonstrating the importance of MPS1 activity for maintaining genome stability in these cell lines. To independently assess the importance of SAC function in $\triangle A P C 7$ and $\triangle A P C 16$ cells, we depleted cells of MAD2 by RNAi and analysed nuclear morphology four days thereafter (Figure 2E and Figure S2F). Consistent with the crucial role of MAD2 in maintaining genomic stability, we quantified a marked decrease in normally sized and shaped nuclei in wild type cells upon MAD2depletion (Figure 2F). Interestingly, however, the decrease in normal nuclei upon MAD2 RNAi was reduced in both $\triangle \mathrm{APC} 7$ and $\triangle \mathrm{APC} 16$ cells (Figure $2 \mathrm{~F}$ ).

Overall, these results indicate that loss of APC7 or APC16 has little impact on mitotic progression, APC/C activity towards CCNB1, and SAC functionality. However, cell lines lacking either APC7 or APC16 appear to rely less on MAD2 for maintaining their genome stability.

\section{Genetic ablation of Mad2 in cells deleted of APC7 or APC16}

As $\triangle \mathrm{APC7}$ and $\triangle \mathrm{APC} 16$ cell lines displayed reduced sensitivity to MAD2 depletion (Figure $2 \mathrm{~F}$ ), we sought to test whether genetic ablation of MAD2 is tolerated in these cell lines. To assess the synthetic viability of MAD2 deletion with the loss of APC7, we mixed equal numbers (i.e. 1:1:1) of wild-type, APC8-mCherry, and APC8-mCherry $\triangle A P C 7$ cells (Figure 3A, Figure S3A) and performed CRISPR-mediated MAD2 deletion in the resulting mixed cell population. After selection, single colonies were analysed for the absence of MAD2 by immunoblotting. We recovered a total of six $\triangle M A D 2$ cell lines, all of which were derived from the APC8-mCherry $\triangle A P C 7$ background (Figure $3 B)$. This result is consistent with MAD2 being essential in human cells and demonstrates that cells lacking APC7 can tolerate loss of MAD2. To confirm the observed synthetic viability and assess whether it also applies to APC16 deletion, we devised an approach facilitating direct deletion of MAD2 from wild type cells along with co-deletion of either APC7 or APC16. For this we GFP-tagged MAD2 endogenously and transfected these cells with a MAD2 deletion construct bearing a selection marker together with a selection-less plasmid encoding a guide RNA targeting either APC7 or APC16 (Figure 3C, Figure S3B). After selection, clonal cell colonies were isolated based on the visually observed loss of GFP fluorescence (indicating loss of MAD2-GFP) and subsequently analysed by immunoblotting for the absence of MAD2-GFP. Concurrent loss of APC7 and APC16 was assessed by immunoblotting and genotyping, respectively. Using this approach, we obtained four $\triangle$ MAD2-GFP $\triangle$ APC7 and six $\triangle$ MAD2-GFP $\triangle A P C 16$ cell lines (Figure 3D, Figure S3C, Figure S3D). As the experimental setup only selects for MAD2 deletion, the strict co-occurrence of either APC7 or APC16 loss with MAD2 deletion indicates that the observed viability is synthetic. Consistent with the deletion of MAD2 and concurrent loss of SAC activity, neither $\triangle A P C 7 \triangle M A D 2$ nor $\triangle M A D 2-$ GFP $\triangle A P C 16$ cells arrested in mitosis upon nocodazole treatment (Figure 3E). Taken together, these results show that genetic deletion of either APC7 or APC16 allows for continued proliferation in absence of MAD2. 


\section{Analysis of cells lacking MAD2}

Loss of SAC activity leads to genomic instability (Dobles et al. 2000, Kops et al. 2005 and Figure 2E, F). We therefore analysed the cellular DNA content of different $\triangle A P C 7 \triangle M A D 2$ and $\triangle M A D 2-$ GFP $\triangle A P C 16$ clonal cell lines by FACS (Figure S4A). A modest increase in polyploid cells was observed in the SAC deficient cell lines compared to wild-type cells, indicating ongoing, yet tolerable chromosomal instability. To further explore the genomic stability of $\triangle A P C 7 \triangle M A D 2$ cells, we compared mitosis and chromosome segregation in $\triangle$ APC7 $\triangle M A D 2$ cells with wild-type cells and wild-type cells depleted of MAD2 by RNAi. To this end, we fluorescently tagged histone $\mathrm{H} 2 \mathrm{~B}$ in wild-type and $\triangle A P C 7 \triangle M A D 2$ cells and analyzed these cells by live cell imaging (Figure $4 A$ ). We observed a decreased time from chromatin condensation to anaphase onset in $\triangle$ APC7 $\triangle M A D 2$ cells compared to wild type cells, consistent with MAD2 causing delayed mitotic progression in wild-type cells (Figure 4B). Wild-type cells depleted of MAD2 by RNAi most frequently (85\%) proceed through mitosis without formation of a metaphase plate, resulting in aberrant or undetectable chromosome segregation (Figure 4A, Figure 4C and Figure S4B). In contrast, $\triangle A P C 7 \triangle M A D 2$ cells frequently (96\%) formed a metaphase plate despite lacking MAD2 function and segregated chromosomes (Figure $4 A$ and Figure $4 C$ ). Compared to wild-type cells, we captured more chromosome segregation errors in $\triangle A P C 7 \triangle M A D 2$ cells in our live cell imaging data (Figure $4 \mathrm{C}$ and Figure $\mathrm{S} 4 \mathrm{~B})$, indicating an increased rate of ongoing segregation errors. As MPS1 acts upstream of MAD2 in the SAC response, we tested whether genetic ablation of MAD2 would relieve cells from the need for MPS1 kinase activity to maintain their genome stability. FACS analysis of $\triangle A P C 7 \triangle M A D 2$ or $\triangle M A D 2-G F P \triangle A P C 16$ cells upon treatment with the MPS1 inhibitor reversine shows a marked increase in cells will $>4 N$ DNA content (Figure 4D). Hence, MAD2 deletion does not relieve these cell lines from the need for MPS1 activity to prevent excessive polyploidy. In summary, cells lacking MAD2 and APC7 display an accelerated mitosis concurrent with increased chromosome segregation errors and require MPS1 activity for genome stability in absence of a functional SAC.

\section{Discussion}

The APC/C complex, composed of 19 subunits, is the largest known ubiquitin ligase. How this large complex assembles in vivo is not fully understood. Here we have deleted the two non-essential, higher eukaryote -specific APC/C subunits APC7 and APC16, and analysed their role in APC/C assembly. This analysis revealed that APC16 is required for $A P C 7$ assembly into the APC/C in vivo, and that APC16 can incorporate into the APC/C independently of APC7. Gratifyingly, these results are in line with in vitro data on an APC3/APC7/APC16 subcomplex (Yamaguchi et al. 2015). Prior to high resolution information about $A P C / C$ structure, a systematic deletion of $A P C / C$ subunits in yeast identified APC/C sub-complexes, which may constitute potential building blocks during APC/C assembly (Thornton et al. 2006). Similarly, the analysis of APC/C assembly upon deletion of individual APC/C subunits may offer an approach to delineate an in vivo APC/C assembly path in human cells and uncover assembly or chaperoning factors involved. Such a strategy will, however, require conditional $A P C / C$ subunit deletions (or depletions), as the majority of $A P C / C$ subunits is essential for cell viability. 
Analysis of key aspects of APC/C function, namely mitotic timing, CCNB1 degradation and response to spindle assembly defects, revealed no significant alterations upon loss of either APC7 or APC16. However, depletion of APC16 by RNAi in human cells and C. elegans results in mitotic phenotypes consistent with impaired APC/C function (Kops et al. 2010). It is currently unclear why APC16 depletion and APC16 deletion result in different phenotypes, but the difference between acute and permanent loss may contribute to this discrepancy. The sole, yet striking, phenotype detected in our study for cells lacking either APC7 or APC16 is their reduced dependence on MAD2 function for viability, indirectly revealing a functional impact of these APC/C subunits in HCT116 cells. The penetrance of genome instability upon MAD2 depletion by RNAi is significantly reduced in $\triangle A P C 7$ and $\triangle A P C 16$ cells compared to wild-type HCT116 cells. This reduced dependence on MAD2 function ultimately allows for genetic ablation of MAD2 in $\triangle A P C 7$ and $\triangle A P C 16$ cell lines. The synthetic viability between loss of MAD2 and deletion of either APC7 or APC16 may be particularly notable given the lack of a pronounced increase in mitotic length in $\triangle A P C 7$ and $\triangle A P C 16$ cells. Our previous work showed that deletion of two APC/C-employed E2 enzymes, UBE2S and UBE2C, provides viability to loss of MAD2 (Wild et al. 2016). $\triangle$ UBE2S $\triangle U B E 2 C$ cells display a significantly prolonged mitosis, and it was therefore rationalized that it is this increased length of mitosis which enables cells to properly segregate the genomic material in absence of SAC activity. In contrast, mitosis was not detectably prolonged in $\triangle \mathrm{APC} 7$ and $\triangle \mathrm{APC} 16$ cells, yet these genetic backgrounds provide synthetic viability to MAD2 deletion. Therefore, even a mild mitotic delay, which may be below the detection limits of our live cell assay, may suffice to render MAD2 function non-essential in $\triangle A P C 7$ and $\triangle A P C 16$ cells. Alternatively, other, yet to be discovered, mechanisms to sustain genome stability in the absence of SAC signalling may exist. In the context of this study we focused on the analysis of mitotic APC/C activity, yet other aspects of APC/C function have been reported and their dependence on either APC7 or APC16 remains to be determined (Harper et al. 2002, Eguren et al. 2011).

Deletion of MAD2 has been shown to be embryonically lethal in mice, and MAD2 haploinsufficiency significantly impairs SAC function and accurate chromosome segregation in both murine and human cells (Dobles et al. 2000, Michel et al. 2001). The first MAD2 deletion from murine cells was reported in the context of concurrent TP53 deletion, possibly reflecting an increased tolerance of TP53 null cells towards aneuploidy (Burds et al. 2005). Subsequently, it was discovered that mice lacking MAD2 in specific cell types survive, albeit with an increased rate of aneuploidy (Foijer et al. 2013) or onset of ultimately lethal diseases (Foijer et al. 2017). It will be of interest to dissect the distinct properties of reported MAD2 knockout cells in terms of their chromosome segregation error rates on the one hand and potentially altered tolerance towards aneuploidy on the other hand.

The kinase MPS1 has established functions outside of SAC signaling (Liu and Winey, 2012). We find that cells lacking MAD2, and thus SAC function, still require MPS1 for maintaining their genome stability. Hence, SAC-independent MPS1 functions, such as its role in chromosome alignment (Jelluma et al. 2008), are essential for genome integrity. This scenario is reminiscent of yeast, an organism in which Mad2 is not essential for viability, yet Mps1 is. Our genetic MAD2 knockout cells could provide a useful tool to further elucidate SAC-independent, essential functions of MPS1. 
Both MPS1 and MAD2 act to maintain the stable euploid state of a cellular genome. The contribution of genomic instability to human disease has been of great research interest ever since the initial observation that aneuploidy is commonly detected in human cancers (Boveri 1902, Kops et al. 2005, Funk et al. 2016). We envision that further genetic interrogations of cellular mechanisms controlling genome stability, such as the SAC, will significantly advance our understanding of mechanisms preventing genome instability on the one side, and mechanisms underlying an increased tolerance towards ongoing genome instability on the other side.

\section{Methods and Materials}

\section{FACS}

To analyse the distribution of cellular DNA content, exponentially growing cells were harvested at $\sim 70 \%$ confluency using trypsin. Cells were pelleted, resuspended in $500 \mu \mathrm{l}$ ice-cold PBS and then permeablized by addition of $500 \mu$ ice-cold ethanol. Samples were incubated on ice for $45 \mathrm{~min}$, pelleted by centrifugation and washed with cold PBS. The cell pellet was resuspended in propidium iodide (PI) staining solution ( $10 \mu \mathrm{g} / \mathrm{ml} \mathrm{PI}$ in PBS) supplemented with RNAse $(25 \mu \mathrm{g} / \mathrm{ml})$ and incubated for $30 \mathrm{~min}$ at $37^{\circ} \mathrm{C}$. Samples were analyzed by flow cytometry using a BD LSR Fortessa (BD Biosciences). Data were analyzed and visualized using the FlowJo software (FlowJo, LLC). The Cell Cycle function in FlowJo was used to quantify cell populations with different DNA content or, in case of perturbation experiments, gates were manually set for one sample and the defined gates then applied to all samples of the same experiment.

\section{$A P C / C$ affinity purification}

APC/C was purified from APC8-mCherry expressing cells using RFP-Trap (RFP-Trap ${ }^{\circledR}$ MA, ChromoTek). For SILAC-based quantification of proteins (Ong et al. 2002), cells were grown in SILAC medium supplemented with natural variants of L-arginine (Arg) and L-lysine (Lys), i.e. $\mathrm{Arg}^{0} / \mathrm{Lys}^{0}$ for the light SILAC condition, or supplemented with isotope labeled variants of Arg and Lys, i.e. $\mathrm{Arg}^{6} / \mathrm{Lys}^{4}$ for the medium and $\mathrm{Arg}^{10} / \mathrm{Lys}^{8}$ for the heavy SILAC condition. For APC/C purification, cells were lysed in RIPA buffer $(50 \mathrm{mM}$ Tris- $\mathrm{HCl} \mathrm{pH} \mathrm{7.5,150} \mathrm{mM} \mathrm{NaCl}, 1 \%$ Nonidet P$40,0.1 \%$ sodium-dodecyl-sulfate, 1 mM EDTA) supplemented with protease inhibitors (Complete protease inhibitor mixture tablets, Roche Diagnostics). Lysates were incubated for $10 \mathrm{~min}$ on ice and cleared by centrifugation at $16,000 \times \mathrm{g}$. Cleared lysates were then incubated on a rotating wheel for 1 hour at $4{ }^{\circ} \mathrm{C}$ with $20 \mu$ of RFP-Trap beads. Beads were washed 3 times with RIPA buffer and eluted with LDS sample buffer (Thermo Fisher Scientific). For SILAC experiments, equal amount of proteins, as determined by Bradford assay (Bio-Rad), were incubated with the RFP-Trap beads. The beads from the different SILAC conditions were washed once separately with RIPA buffer, combined into one new tube and subsequently washed together 3 times with RIPA buffer. Eluates were analysed by SDS-PAGE followed by immunoblotting or mass spectrometry.

\section{Mass spectrometry}

Samples in LDS sample buffer were incubated with dithiothreitol $(10 \mathrm{mM})$ for $10 \mathrm{~min}$ at $70{ }^{\circ} \mathrm{C}$ and subsequently with chloroacetamide $(5.5 \mathrm{mM})$ for $60 \mathrm{~min}$ at $25^{\circ} \mathrm{C}$. Proteins were separated on a 
4\%-12\% gradient SDS-PAGE, stained with colloidal coomassie blue, and digested using in-gel digestion method (Jensen et al. 1999). In brief, gel lanes were cut into six fractions and each gel piece was further sliced into smaller pieces ( $1 \mathrm{~mm})$. Gel pieces were destained with $50 \%$ ethanol in $25 \mathrm{mM}$ ammonium bicarbonate $(\mathrm{pH} 8.0)$ on a rotating wheel at room temperature and dehydrated with 100\% ethanol. Trypsin (in $25 \mathrm{mM}$ ammonium bicarbonate $\mathrm{pH}$ 8.0) was added to the dry gel pieces and incubated overnight at $37^{\circ} \mathrm{C}$. The trypsin digestion was stopped by addition of trifluoroacetic acid ( $0.5 \%$ final concentration) and peptides were extracted from the gel pieces by stepwise increase in acetonitrile concentration (to 100\% final). Next, acetonitrile was removed by centrifugal evaporation and peptides were purified by a C18 reversed-phase packed Stage-Tip. Peptide fractions eluted from Stage-Tips were analyzed on a quadrupole Orbitrap (Q-Exactive, Thermo Scientific) mass spectrometer equipped with a nanoflow HPLC system (Thermo Scientific). Peptide samples were loaded onto $\mathrm{C} 18$ reversed-phase columns and eluted with a linear gradient from 8 to $40 \%$ acetonitrile containing 0.5\% acetic acid in 105 min gradient. The Q-Exactive was operated in the data dependent mode automatically switching between single-mass-spectrometry and tandem-mass-spectrometry acquisition. Survey full-scan MS spectra (m/z 300-1700) were acquired in the Orbitrap. The 10 most intense ions were sequentially isolated and fragmented by higher-energy C-trap dissociation (HCD). Peptides with unassigned charge states, as well as peptides with charge state less than +2 were excluded from fragmentation. Fragment spectra were acquired in the Orbitrap mass analyzer.

Raw MS data were analyzed by the MaxQuant software (Cox and Mann 2008). Mass spectra were searched against protein sequences from the UniProt knowledge base using the Andromeda search engine (Cox et al. 2011). Spectra were searched with a mass tolerance of $6 \mathrm{ppm}$ for precursor ions, $20 \mathrm{ppm}$ for fragment ions, strict trypsin specificity and allowing up to two missed cleavage sites. Cysteine carbamido methylation was searched as a fixed modification, whereas amino-terminal protein acetylation and methionine oxidation were searched as variable modifications. A false discovery rate of less than one percent was achieved using target-decoy search strategy (Elias and Gygi 2007) and a posterior error probability filter.

\section{Antibodies}

$\alpha$-MAD2 (EMD Millipore, MABE866), $\alpha$-APC1 (Cell Signaling Technology, APC1 (D1E9D) Rabbit mAb \#13329), $\alpha$-APC2 (Cell Signaling Technology, APC2 Antibody \#12301), $\alpha$-APC7 (Bethyl laboratories, A302-551A), $\alpha$-APC8 (Cell Signaling Technology, APC8 (D5O2D) Rabbit mAb \#15100), $\alpha$-APC11 (Cell Signaling Technology, APC11 (D1E7Q) Rabbit mAb \#14090), $\alpha$-GAPDH (Merck Millipore, AntiGAPDH Antibody, ABS16), $\alpha$-GFP (Cell Signaling Technology, GFP (D5.1) XP ${ }^{\circledR}$ Rabbit mAb), $\alpha-C C N B 1$ (BD Pharmingen, Purified Mouse Anti-Cyclin B1, Clone GNS-1)

\section{Genome engineering}

Crispr/Cas9 was applied to tag or delete genes of interest. DNA oligonucleotides encoding the guide RNAs were cloned into pX330 (Cong et al.) and co-transfected with donor plasmids to achieve the desired modification within the genome of HCT116 cells. Donor plasmids generally contain homology arms spanning approximately $500 \mathrm{bp}$ from each side of the cutting site (as designated by the guide RNAs) and a selection marker, providing resistance towards puromycin, G418, zeocin, hygromycin, blasticidin or NTC (Kochupurakkal and Iglehart). For tagging, mCherry, 
EGFP, mVenus or mCerulean3 (Markwardt et al.) were fused in frame to the last exon of the gene of interest. After selection, clonal cell lines were analysed by genomic PCR and/or immunoblotting to screen for the desired genomic modification. The following guide RNAs (including PAM motif shown in bold) were used (when two guide RNAs are listed both were used simultaneously):

For gene tagging:

APC8: CCATAGTTGGCTACTCTCAAGCC

MAD2: aacacaatcactaaattgcacgg and tgaccttttccagcagtgagtgg

CCNB1: TGTAACTTGTAAACTTGAGTTGG

H2B: CCACGCAtgttttcaataaatga and aatcatttcattcaaaagggggg

For gene deletions:

dAPC7: TGCGGGACATGGCGGCCGCGGGG

dAPC7intron: agcgcgactgtcacatcgctagg and agctcagggacccagcctcctgg

dAPC16: GCCCTTTTCACCTACCCCAAAGG

dMAD2: CCCTGCGCGGGAGCGCCGAAATC

The following table summarizes the cell lines generated in this study:

\begin{tabular}{|c|c|c|c|}
\hline no. & cell line & parental line & additional resistance* \\
\hline 1 & Apc8-mCherry & HCT116 & G418 \\
\hline 2 & Apc8-mCherry $\triangle \mathrm{APC7}$ & no. 1 & hygromycin / zeocin \\
\hline 3 & Apc8-mCherry $\triangle \mathrm{APC16}$ & no. 1 & hygromycin / zeocin \\
\hline 4 & CCNB1-mCerulean3 & HCT116 & blasticidin \\
\hline 5 & CCNB1-mCerulean3 H2BD-mVenus & no. 4 & NTC \\
\hline 6 & CCNB1-mCerulean3 $\triangle \mathrm{APC7}$ & no. 4 & hygromycin / zeocin \\
\hline 7 & CCNB1-mCerulean3 $\triangle \mathrm{APC7} H$ 2BD-mVenus & no. 6 & NTC \\
\hline 8 & CCNB1-mCerulean3 $\triangle \mathrm{APC16}$ & no. 4 & hygromycin / zeocin \\
\hline 9 & CCNB1-mCerulean3 $\triangle$ APC16 H2BD-mVenus & no. 8 & NTC \\
\hline 10 & Apc8-mCherry $\triangle \mathrm{APC7} \triangle \mathrm{Mad} 2$ & no. 2 & puromycin / blasticidin \\
\hline 11 & Apc8-mCherry Mad2-EGFP & no. 1 & puromycin \\
\hline 12 & Apc8-mCherry $\triangle$ Mad2-EGFP $\triangle$ APC7 & no. 11 & hygromycin \\
\hline 13 & Apc8-mCherry $\triangle$ Mad2-EGFP $\triangle$ APC16 & no. 11 & hygromycin \\
\hline 14 & H2BD-mCerulean3 & НCT116 & blasticidin \\
\hline 15 & Apc8-mCherry $\triangle \mathrm{APC7} \triangle \mathrm{Mad} 2 \mathrm{H}$ 2BD-mCerulean3 & no. 10 & NTC \\
\hline
\end{tabular}

*if stated, the two selection markers were used simultaneously (offering a stringent selection regime for targeting both alleles of the gene of interest)

\section{Live cell microscopy}

Cells were grown in 24 well plates suited for microscopy (Imaging Plate CG, zell-kontakt). For live cell imaging, cells were seeded into FluoroBrite DMEM medium (Thermo Fisher Scientific) supplemented with $10 \%$ FBS and $4 \mathrm{mM} \mathrm{L-glutamine.} \mathrm{Live} \mathrm{cell} \mathrm{imaging} \mathrm{was} \mathrm{performed} \mathrm{on} \mathrm{an}$ Olympus ScanR microscope using a 20 x objective. Images were taken continuously every 3 min 
acquiring 6 z-stacks of $1.5 \mu \mathrm{m}$ (H2B-mCerulean3 expressing cell lines) or every 5 min acquiring $4 \mathrm{z}$ stacks of $2 \mu \mathrm{m}$ (CCNB1-mCerulean3 and H2B-mVenus expressing cell lines).

\section{RNAi}

Cells were seeded into a 24-well plate and transfected with siRNAs 24 hours later using RNAiMAX (Lipofectamine ${ }^{\circledR}$ ) as transfection reagent according to the manufactures guidelines. For MAD2 depletion, the following siRNA was used: CGCCUUCGUUCAUUUACUAtt (Silencer Select, Thermo Fisher Scientific). Silencer Select Negative Control \#1 siRNA (s813, Thermo Fisher Scientific) was used as a negative control. The final concentration of siRNAs was $5 \mathrm{nM}$. 24 hours after siRNA transfection, cells were trypsinized and reseeded into 24-well plates suitable for microscopy (Imaging Plate CG, zell-kontakt). 72 hours later (96 hours after siRNA transfection), Hoechst (Hoechst 33342, Life Technologies, H3570) was added directly to the medium and cells imaged with an Olympus ScanR microscope using a $20 \mathrm{x}$ objective. After imaging, cell lysates were prepared from the imaged 24-wells using RIPA buffer $(50 \mathrm{mM}$ Tris- $\mathrm{HCl} \mathrm{pH} \mathrm{7.5,} 150 \mathrm{mM} \mathrm{NaCl}, 1 \%$ Nonidet P-40, 0.1\% sodium-dodecyl-sulfate, 1 mM EDTA). Samples containing equal amounts of protein, as determined by Bradford assay (Bio-Rad), were mixed with LDS-sample buffer and analysed by SDS-PAGE followed by immunoblotting. For live cell imaging, cells were transfected with MAD2 siRNA/RNAiMAX mix 32 hours prior to imaging.

\section{Image analysis}

Images acquired by live cell microscopy were analysed using the Imaris Image analysis software (Bitplane). Nuclear CCNB1 influx was visually scored as the first frame prior to mitosis in which nuclear CCNB1-mCerulean3 intensity equalled or exceeded cytoplasmic CCNB1-mCerulean3 intensity. Anaphase onset was scored as the first frame in which two separate chromosome masses were observed in the $\mathrm{H} 2 \mathrm{~B}-\mathrm{mVenus}$ channel after metaphase plate formation. To obtain CCNB1 degradation rates, z-projections (median projections) were generated in Fiji and chromatin objects (Surfaces) were generated in Imaris using the Magic Wand tool on the H2B-mVenus channel. Mean CCNB1-Cerulean3 intensities of the defined chromatin objects were extracted to obtain CCNB1 degradation trajectories for individual cells. The CCNB1 degradation rate at anaphase onset was calculated as the slope of the linear fit for the mean CCNB1 intensities one frame before anaphase onset, at anaphase onset and one frame after anaphase onset. For H2BmCerulean 3 expressing cells, mitotic timing was calculated from the onset of chromosome condensation to anaphase onset. To score chromosome segregation errors, each analysed cell was visually scanned through the six acquired z-stacks for observable chromosome segregation defects around anaphase onset.

To analyse nuclear size and shape upon Mad2 depletion, images of Hoechst stained nuclei were visually separated into two categories: normally sized and shaped nuclei (i.e. normal nuclei), and enlarged and irregularly shaped nuclei (i.e. aberrant nuclei).

\section{Genomic analysis of APC16 locus}

The genomic locus of APC16 encompassing the sequence targeted by the guide RNA was analysed with the following primer set: gAPC16fw (5`-gcgcGGTACCgttcaaaacctgactgatattttggcctgagac) and 
gAPC16rev (5`-gcgcCTTAAGcgtgcccagccctgactctgcctttaacctgg). KOD Xtreme Hot Start DNA Polymerase (Novagen, Toyobo) was used according to the manufactures protocol to amplify the APC16 locus. GeneRuler 1 kb DNA Ladder (Thermo Fisher Scientific) was used as a DNA marker. To sequence potential indels within the APC16 locus, the PCR product was cloned into pCDNA3.1/ZEO (+) (Thermo Fisher Scientific, Invitrogen) using the Kpnl and AfllI restriction sites.

\section{Drug treatments}

To assess spindle assembly checkpoint functionality, cells were treated with $200 \mathrm{nM}$ nocodazole (Sigma Aldrich, M1404) for indicated times. To assay for the cellular dependence on MPS1 kinase activity, cells were treated with $0.5 \mu \mathrm{M}$ reversine (MedChemexpress, HY-14711) for indicated times.

\section{Plasmids and transfections}

The coding sequence of APC16 was cloned Nhel/BamHI into pEGFP-N2 (Clontech), and the resulting construct (pAPC16-EGFP) was verified by sequencing. For plasmid transfection, $5 \mu \mathrm{g}$ of plasmid (pAPC16-EGFP) was incubated in DMEM medium (without any supplements) with 15 ul TurboFect (Thermo Fisher) for $20 \mathrm{~min}$ at room temperature and then added to $50 \%$ confluent cells in a $10 \mathrm{~cm}$ dish. APC/C affinity purification was performed 32 hours after transfection.

\section{Acknowledgements}

We thank the members of our group for their help and discussions. We thank Rajat Gupta for sharing plasmids and Elina Maskey for providing excellent technical assistance. CC is supported by the Hallas Møller Investigator Fellowship from the Novo Nordisk Foundation (NNF140C0008541). This project has received funding from the European Research Council (ERC) under the European Union's Horizon 2020 research and innovation program (grant agreement No 648039). We thank Dr. Simone Schopper from the CPR Mass Spectrometry Platform for her assistance with maintenance and support of the platform. We thank Gelo dela Cruz from the Flow Cytometry Core Facility at the NNF Center for Stem Cell Biology (DanStem) and Jutta Bulkescher from the CPR Protein Imaging Platform for their technical assistance with flow cytometry and microscopy, respectively. The Center for Chromosome Stability is supported by the Danish National Research Foundation. The Novo Nordisk Foundation Center for Protein Research is supported financially by the Novo Nordisk Foundation (Grant agreement: NNF14CC0001).

\section{Author contributions}

TW and MB designed and performed the experiments, and analyzed the data. GK helped with analysis of live cell imaging data. TW, MB and CC wrote the manuscript. CC supervised the research. All authors read and commented on the manuscript.

\section{Competing financial interests}

The authors have no conflict of interest to declare. 


\section{References}

Alfieri et al. Molecular basis of APC/C regulation by the spindle assembly checkpoint. Nature. 2016 Aug 25;536(7617):431-436. doi: 10.1038/nature19083. Epub 2016 Aug 10.

Burds et al. Generating chromosome instability through the simultaneous deletion of Mad2 and p53. Proc Natl Acad Sci U S A. 2005 Aug 9;102(32):11296-301. Epub 2005 Jul 29.

Chang et al. Atomic structure of the APC/C and its mechanism of protein ubiquitination. Nature. 2015 Jun 25;522(7557):450-454. doi: 10.1038/nature14471. Epub 2015 Jun 15.

Cong et al. Multiplex genome engineering using CRISPR/Cas systems. Science. 2013 Feb 15;339(6121):819-23. doi: 10.1126/science.1231143. Epub 2013 Jan 3.

Cox J, Mann M. MaxQuant enables high peptide identification rates, individualized p.p.b.-range mass accuracies and proteome-wide protein quantification. Nat Biotechnol. 2008 Dec;26(12):1367-72.

Cox J, Neuhauser N, Michalski A, Scheltema RA, Olsen JV, Mann M. Andromeda: a peptide search engine integrated into the MaxQuant environment. J Proteome Res. 2011 Apr 1;10(4):1794-805.

Dobles et al. Chromosome missegregation and apoptosis in mice lacking the mitotic checkpoint protein Mad2. Cell. 2000 Jun 9;101(6):635-45.

Dube et al. Localization of the coactivator Cdh1 and the cullin subunit Apc2 in a cryo-electron microscopy model of vertebrate APC/C. Mol Cell. 2005 Dec 22;20(6):867-79.

Eguren et al. Non-mitotic functions of the Anaphase-Promoting Complex. Semin Cell Dev Biol. 2011 Aug;22(6):572-8. doi: 10.1016/j.semcdb.2011.03.010. Epub 2011 Mar 23.

Elias and Gygi: Target-decoy search strategy for increased confidence in large-scale protein identifications by mass spectrometry. Nat Methods. 2007 Mar;4(3):207-14.

Foijer et al. Spindle checkpoint deficiency is tolerated by murine epidermal cells but not hair follicle stem cells. Proc Natl Acad Sci U S A. 2013 Feb 19;110(8):2928-33. doi:

10.1073/pnas.1217388110. Epub 2013 Feb 4.

Foijer et al. Deletion of the MAD2L1 spindle assembly checkpoint gene is tolerated in mouse models of acute T-cell lymphoma and hepatocellular carcinoma. Elife. 2017 Mar 20;6. pii: e20873. doi: 10.7554/eLife.20873.

Funk et al. Living in CIN: Mitotic Infidelity and Its Consequences for Tumor Promotion and Suppression. Dev Cell. 2016 Dec 19;39(6):638-652. doi: 10.1016/j.devcel.2016.10.023. 
Garnett et al. UBE2S elongates ubiquitin chains on APC/C substrates to promote mitotic exit. Nat Cell Biol. 2009 Nov;11(11):1363-9. doi: 10.1038/ncb1983. Epub 2009 Oct 11.

Green et al. A high-resolution C. elegans essential gene network based on phenotypic profiling of a complex tissue. Cell. 2011 Apr 29;145(3):470-82. doi: 10.1016/j.cell.2011.03.037.

Harper et al. The anaphase-promoting complex: it's not just for mitosis any more. Genes Dev. 2002 Sep 1;16(17):2179-206.

Hershko et al. Components of a system that ligates cyclin to ubiquitin and their regulation by the protein kinase cdc2. J Biol Chem. 1994 Feb 18;269(7):4940-6.

Herzog et al. Structure of the anaphase-promoting complex/cyclosome interacting with a mitotic checkpoint complex. Science. 2009 Mar 13;323(5920):1477-81. doi: 10.1126/science.1163300.

Hubner et al. Quantitative proteomics combined with BAC TransgeneOmics reveals in vivo protein interactions. J Cell Biol. 2010 May 17;189(4):739-54. doi: 10.1083/jcb.200911091.

Hutchins et al. Systematic analysis of human protein complexes identifies chromosome segregation proteins. Science. 2010 Apr 30;328(5978):593-9. doi: 10.1126/science.1181348. Epub 2010 Apr 1.

Jelluma et al. Mps1 phosphorylates Borealin to control Aurora B activity and chromosome alignment. Cell. 2008 Jan 25;132(2):233-46. doi: 10.1016/j.cell.2007.11.046.

Jensen ON, Wilm M, Shevchenko A, Mann M. Sample preparation methods for mass spectrometric peptide mapping directly from 2-DE gels. Methods Mol Biol. 1999;112:513-30.

Kochupurakkal and Iglehart. Nourseothricin N-Acetyl Transferase: A Positive Selection Marker for Mammalian Cells. 2013 PLoS One. 2013 Jul 4;8(7):e68509. doi: 10.1371/journal.pone.0068509. Print 2013.

Kops et al. On the road to cancer: aneuploidy and the mitotic checkpoint. Nat Rev Cancer. 2005 Oct;5(10):773-85.

Kops et al. APC16 is a conserved subunit of the anaphase-promoting complex/cyclosome. J Cell Sci. 2010 May 15;123(Pt 10):1623-33. doi: 10.1242/jcs.061549. Epub 2010 Apr 14.

Liu and Winey. The MPS1 family of protein kinases. Annu Rev Biochem. 2012;81:561-85. doi: 10.1146/annurev-biochem-061611-090435. Epub 2012 Apr 5.

London and Biggins. Signalling dynamics in the spindle checkpoint response. Nat Rev Mol Cell Biol. 2014 Nov;15(11):736-47. doi: 10.1038/nrm3888. Epub 2014 Oct 10. 
Markwardt et al. An improved cerulean fluorescent protein with enhanced brightness and reduced reversible photoswitching. 2011. PLoS One. 2011 Mar 29;6(3):e17896. doi:

10.1371/journal.pone.0017896.

Meyer and Rape. Enhanced protein degradation by branched ubiquitin chains. Cell. 2014 May 8;157(4):910-21. doi: 10.1016/j.cell.2014.03.037.

Michel et al. MAD2 haplo-insufficiency causes premature anaphase and chromosome instability in mammalian cells. Nature. 2001 Jan 18;409(6818):355-9.

Michel et al. Complete loss of the tumor suppressor MAD2 causes premature cyclin B degradation and mitotic failure in human somatic cells. Proc Natl Acad Sci U S A. 2004 Mar 30;101(13):4459-64. Epub 2004 Mar 15.

Min et al. Efficient APC/C substrate degradation in cells undergoing mitotic exit depends on K11 ubiquitin linkages. Mol Biol Cell. 2015 Dec 1;26(24):4325-32. doi: 10.1091/mbc.E15-02-0102. Epub 2015 Oct 7.

Meraldi et al. Timing and checkpoints in the regulation of mitotic progression. Dev Cell. 2004 Jul;7(1):45-60.

Ohta et al. The protein composition of mitotic chromosomes determined using multiclassifier combinatorial proteomics. Cell. 2010 Sep 3;142(5):810-21. doi: 10.1016/j.cell.2010.07.047.

Ong SE, Blagoev B, Kratchmarova I, Kristensen DB, Steen H, Pandey A, Mann M.. Stable isotope labeling by amino acids in cell culture, SILAC, as a simple and accurate approach to expression proteomics. Mol Cell Proteomics. 2002 May;1(5):376-86.

Pal et al. Structurally related TPR subunits contribute differently to the function of the anaphasepromoting complex in Drosophila melanogaster. J Cell Sci. 2007 Sep 15;120(Pt 18):3238-48.

Peters JM. The anaphase promoting complex/cyclosome: a machine designed to destroy. Nat Rev Mol Cell Biol. 2006 Sep;7(9):644-56. Epub 2006 Aug 9.

Pines J. Cubism and the cell cycle: the many faces of the APC/C. Nat Rev Mol Cell Biol. Nat Rev Mol Cell Biol. 2011 Jun 2;12(7):427-38. doi: 10.1038/nrm3132.

Poser et al. BAC TransgeneOmics: a high-throughput method for exploration of protein function in mammals. Nat Methods. 2008 May;5(5):409-15. doi: 10.1038/nmeth.1199. Epub 2008 Apr 6.

Primorac and Musacchio. Panta rhei: the APC/C at steady state. J Cell Biol. $2013 \mathrm{Apr}$

15;201(2):177-89. doi: 10.1083/jcb.201301130. 
Shakes et al. emb-1 encodes the APC16 subunit of the Caenorhabditis elegans anaphasepromoting complex. Genetics. 2011 Oct;189(2):549-60. doi: 10.1534/genetics.111.131714. Epub $2011 \mathrm{Jul} 20$.

Sivakumar and Gorbsky. Spatiotemporal regulation of the anaphase-promoting complex in mitosis. Nat Rev Mol Cell Biol. 2015 Feb;16(2):82-94. doi: 10.1038/nrm3934.

Sudakin et al. Checkpoint inhibition of the APC/C in HeLa cells is mediated by a complex of BUBR1, BUB3, CDC20, and MAD2. J Cell Biol. 2001 Sep 3;154(5):925-36.

Thornton and Toczyski. Securin and B-cyclin/CDK are the only essential targets of the APC. Nat Cell Biol. 2003 Dec;5(12):1090-4. Epub 2003 Nov 23.

Thornton et al. An architectural map of the anaphase-promoting complex. Genes Dev. 2006 Feb 15;20(4):449-60.

Townsley et al. Dominant-negative cyclin-selective ubiquitin carrier protein E2-C/UbcH10 blocks cells in metaphase. Proc Natl Acad Sci U S A. 1997 Mar 18;94(6):2362-7.

Wild et al. The Spindle Assembly Checkpoint Is Not Essential for Viability of Human Cells with Genetically Lowered APC/C Activity. Cell Rep. 2016 Mar 1;14(8):1829-40. doi:

10.1016/j.celrep.2016.01.060. Epub 2016 Feb 18.

Williamson et al. Identification of a physiological E2 module for the human anaphase-promoting complex. Proc Natl Acad Sci U S A. 2009 Oct 27;106(43):18213-8. doi: 10.1073/pnas.0907887106. Epub 2009 Oct 12.

Wu et al. UBE2S drives elongation of K11-linked ubiquitin chains by the anaphase-promoting complex. Proc Natl Acad Sci U S A. 2010 Jan 26;107(4):1355-60. doi: 10.1073/pnas.0912802107. Epub 2010 Jan 6.

Yamaguchi et al. Structure of an APC3-APC16 complex: insights into assembly of the anaphasepromoting complex/cyclosome. J Mol Biol. 2015 Apr 24;427(8):1748-64. doi:

10.1016/j.jmb.2014.11.020. Epub 2014 Dec 6.

Yamaguchi et al. Cryo-EM of Mitotic Checkpoint Complex-Bound APC/C Reveals Reciprocal and Conformational Regulation of Ubiquitin Ligation. Mol Cell. 2016 Aug 18;63(4):593-607. doi: 10.1016/j.molcel.2016.07.003. Epub 2016 Aug 10.

Yu et al. Identification of a novel ubiquitin-conjugating enzyme involved in mitotic cyclin degradation. Curr Biol. 1996 Apr 1;6(4):455-66. 


\section{Figure Legends}

\section{Figure 1}

APC16 is required for the assembly of $A P C 7$ into the $A P C / C$.

A) Scheme of triple SILAC setup for MS-based analysis of APC/C composition. APC8-mCherry expressing wild-type, $\triangle \mathrm{APC7}$, or $\triangle \mathrm{APC} 16$ cells were SILAC labelled as indicated and APC/C was purified using mCherry affinity beads. As a control, a mock pull-down was performed from light SILAC labelled cells.

B) SILAC ratios for APC/C subunits enriched from APC8-mCherry wild-type and APC8-mCherry $\triangle A P C 7$ cells. APC/C was purified with mCherry pulldowns from wild-type (medium SILAC condition) and $\triangle \mathrm{APC7}$ cells (heavy SILAC condition) and analysed by mass spectrometry. Mock pull-down from wild-type HCT116 cells served as control (light SILAC condition). The table shows combined SILAC ratios for all APC/C subunits detected in three technical replicates (n.d. $=$ not determined).

C) Analysis of APC/C composition in $\triangle A P C 7$ cells. APC/C was purified via APC8-mCherry pulldowns from APC8-mCherry and APC8-mCherry $\triangle \mathrm{APC7}$ cells (from two independent $\triangle A P C 7$ clonal cell lines) and subsequently analyzed by immunoblotting using indicated antibodies. Wild-type cells were used as a control for unspecific binding to the affinity beads. GAPDH levels were analysed to verify equal amount of input for the different cell lines.

D) SILAC ratios for APC/C subunits enriched from APC8-mCherry and APC8-mCherry $\triangle A P C 16$ cells. The analysis was performed as described in $B$ ).

E) Immunoblot analysis of APC/C composition in $\triangle \mathrm{APC} 16$ cells with indicated antibodies. APC/C was purified via APC8-mCherry pulldowns from APC8-mCherry cells and from APC8mCherry $\triangle$ APC16 cells. Indicated samples were transiently transfected with APC16-EGFP 32 hours prior to the APC/C pulldown. Wild-type cells were used as a control for unspecific binding to the affinity beads.

\section{Figure 2}

Analysis of mitotic $A P C / C$ function in $\triangle A P C 7$ and $\triangle A P C 16$ cells.

A) Time between nuclear CCNB1 influx and anaphase onset for indicated cell lines. Wild-type, $\triangle \mathrm{APC} 7$ and $\triangle \mathrm{APC} 16$ cell lines expressing mVenus-tagged histone $\mathrm{H} 2 \mathrm{~B}$ and mCerulean3tagged CCNB1 were imaged every 5 min. The data shows time from nuclear CCNB1 influx to anaphase onset for individual cells. Cells with identical timing are depicted as a box and the size of each box is scaled according to the percentage they contribute to the whole population of the respective cell line. The mean timing and the standard deviation are stated on top. The median timing is drawn as a black line. Results of three independent experiments are shown and the number $(n)$ of analysed cells is stated for each cell line. A two-tailed t-test was performed to calculate significance $(p<0.01=$ significant; $n$.s. $=$ nonsignificant).

B) CCNB1 degradation rates around anaphase onset in indicated cell lines (from experiment shown in A.). The slope of a linear fit for the measured decrease in CCNB1-mCerulean3 intensities around anaphase onset is plotted for individual cells. The number of analysed cells is given as $\mathrm{n}$. The table shows the mean CCNB1 degradation rate and its standard 
deviation. The median CCNB1 degradation rate is drawn as a black line. A two-tailed t-test was performed to calculate significance ( $p<0.01$ = significant; $n . s .=$ non-significant)).

C) SILAC ratios for APC/C and MCC subunits detected in mass spectrometry analysis of APC8mCherry pulldown with or without SAC activation. APC/C was purified via APC8-mCherry pulldowns from untreated cells (medium SILAC condition) and cells treated with $20 \mathrm{nM}$ nocodazole (noc) for 18 hours (heavy SILAC condition). Depicted are the combined SILAC ratios from three technical replicates. The light SILAC condition was used as a reference for unspecific binding to the affinity beads.

D) SILAC ratios for APC/C and MCC subunits detected in mass spectrometry analysis of APC8mCherry pulldown from APC8-mCherry $\triangle A P C 7$ cells as described in C).

E) Indicated cell lines were treated with control siRNA or MAD2 targeting siRNA for 96 hours, stained with Hoechst and imaged. Representative images from one of the three independent experiments are shown.

F) Quantification of normal nuclei from experiments described in E). From each experiment at least 500 cells were analysed per condition and the cumulative percentage of normal nuclei from all three experiments is shown.

\section{Figure 3}

\section{Loss of APC7 or APC16 provides synthetic viability to MAD2 deletion.}

A) Strategy for assessing the synthetic viability of MAD2 deletion with the $\triangle A P C 7$ genotype. An equal number of wild-type, APC8-mCherry and APC8-mCherry $\triangle A P C 7$ cells were mixed and seeded together, resulting in a mixed cell population with one-third of cells lacking APC7. The genomic MAD2 locus was then targeted by Crispr/Cas9 using a selectable donor plasmid designed to disrupt the MAD2 gene. After selection, each clonal cell line was analysed by immunoblotting to assess loss of MAD2 and to determine its parental cell line.

B) Analysis of APC7 and MAD2 expression in the six clonal $\triangle M A D 2$ cell lines retrieved from the setup outlined in A). GAPDH levels were analysed as a loading control. Note that all six retrieved clonal cell lines derive from APC8-mCherry $\triangle A P C 7$ cells.

C) Scheme of Crispr/Cas9-based MAD2-GFP synthetic viability assay. Cells expressing endogenously GFP-tagged MAD2 (MAD2-GFP) were transfected with a selectable deletion cassette for the MAD2 gene along with a plasmid encoding a guide RNA targeting either APC7 or APC16. After selection, cell colonies were microscopically inspected for loss of MAD2-GFP fluorescence. Cell colonies lacking green fluorescence were then analysed by immunoblotting for loss of MAD2 expression. The status of APC7 and APC16 was assessed by immunoblotting or sequencing of the genomic locus, respectively.

D) Immunoblot analysis of the four clones retrieved from the MAD2-GFP synthetic viability assay performed in combination with an APC7 targeting guide RNA. Note that all retrieved clonal cell lines lost expression of APC7.

E) Analysis of SAC functionality in $\triangle \mathrm{APC7} \triangle \mathrm{MAD2}$ and $\triangle \mathrm{MAD2-GFP} \triangle \mathrm{APC} 16$ cells. Cellular DNA from wild-type, $\triangle A P C 7 \triangle M A D 2$ and $\triangle M A D 2-G F P \triangle A P C 16$ cells, with or without 18 hours of $20 \mathrm{nM}$ nocodazole, was stained with propidium iodide and analysed by FACS. The tables show the percentage of cells with the respective $(2 N, 2 N-4 N, 4 N$ and $>4 N)$ DNA content.

\section{Figure 4}

\section{Analysis of mitosis in $\triangle A P C 7 \triangle M A D 2$ cells.}


A) Representative images of mitosis observed for indicated cell lines expressing H2BmCerulean3. The frames scored as chromosome condensation and anaphase onset are indicated with the first and second arrow, respectively. Note that no anaphase onset was scored for cells that failed to form a metaphase plate in the MAD2 RNAi condition.

B) Quantification of timing from chromatin condensation to anaphase onset from experiment shown in A). Cells with identical timing are illustrated as a scaled box (as described in Figure 2A). Mean timing and the standard deviation are stated on top, median timing is drawn as a black line. Results of two independent experiments are shown and the number of analysed cells is stated as n. A two-tailed t-test was performed to calculate significance.

C) Table summarizing observed chromosome segregation errors in indicated cell lines and conditions.

D) FACS-profiles of $\triangle M A D 2 \triangle A P C 7$ and $\triangle M A D 2-G F P \triangle A P C 16$ cells treated with reversine. Cellular DNA from wild-type, $\triangle \mathrm{APC7} \triangle \mathrm{MAD} 2$ and $\triangle \mathrm{MAD2}-\mathrm{GFP} \triangle \mathrm{APC} 16$ cells, with or without 48 hours of $0.5 \mu \mathrm{M}$ reversine, was stained with propidium iodide and analysed by FACS. The table shows the percentage of cells with the respective $(2 N-4 N$ and $>4 N)$ DNA content.

\section{Supplemental figure 1}

A) Cell lines generated to analyse APC/C composition upon deletion of either APC7 or APC16. Immunoblot analysis of wild-type, APC8-mCherry, APC8-mCherry $\triangle$ APC7 and APC8mCherry $\triangle A P C 16$ cell lines using indicated antibodies. Two independent $\triangle A P C 7$ and three independent $\triangle \mathrm{APC} 16$ clonal cell lines are shown. GAPDH levels were analysed as a loading control.

B) Genomic APC16 locus from wild-type, APC8-mCherry and APC8-mCherry $\triangle$ APC16 cells analysed by PCR. The used primer pair amplifies an approximately 600 base pair (bp) product from a wild-type APC16 locus and an approximately 2300 or 2900 bp product upon genomic insertion of the deletion cassette. Note that biallelic disruption of the APC16 locus was performed using two deletion cassettes bearing different selection markers, which results in two differently sized PCR products. Three independent $\triangle A P C 16$ clonal cell lines are shown.

C) Analysis of APC/C composition in $\triangle \mathrm{APC} 16$ cells. APC/C was purified via APC8-mCherry pulldowns from APC8-mCherry and APC8-mCherry $\triangle$ APC16 cells (from three independent $\triangle \mathrm{APC} 16$ clonal cell lines) and subsequently analyzed by immunoblotting using indicated antibodies. Wild-type cells served as a control for unspecific binding to the affinity beads. GAPDH levels were analysed to verify equal amount of input for the different cell lines.

\section{Supplemental figure 2}

A) Immunoblot analysis of cell lines used for live cell imaging data shown in Figure 2A and 2B. Lysates from indicated cell lines were separated by SDS-PAGE, blotted and analysed with indicated antibodies. GAPDH levels were analysed to control for equal loading.

B) Genomic APC16 locus from wild-type and CCNB1-mCerulean H2B-mVenus $\triangle A P C 16$ cells analysed by PCR as described in Figure S1B.

C) Representative example images extracted from time-lapse imaging experiments analysed in Figure 2A and Figure 2B. For the different cell lines, the CCNB1 influx frame (CCNB1- 
mCerulean3 channel) and anaphase onset frame (H2B-mVenus) are indicated as the first and second arrow, respectively.

D) Analysis of cellular DNA content in wild-type, $\triangle \mathrm{APC7}$ and $\triangle \mathrm{APC} 16$ cells upon 18 hours of nocodazole treatment. The DNA content in wild-type, $\triangle A P C 7$ and $\triangle A P C 16$ cells, grown with or without 18 hours of $20 \mathrm{nM}$ nocodazole, was analyzed with propidium iodide staining and flow cytometry. The tables show the percentage of cells with the respective $(2 \mathrm{~N}, 2 \mathrm{~N}$ $4 \mathrm{~N}, 4 \mathrm{~N}$ and $>4 \mathrm{~N}$ ) DNA content.

E) The DNA content in wild-type, $\triangle \mathrm{APC7}$ and $\triangle \mathrm{APC16}$ cells, grown with or without $0.5 \mu \mathrm{M}$ reversine for 48 or 96 hours, was analyzed with propidium iodide staining and flow cytometry. The histogram of one representative technical replicate is shown and the percentage of cells with $2 \mathrm{~N}-4 \mathrm{~N}$ (including both $2 \mathrm{~N}$ and $4 \mathrm{~N}$ ) and $>4 \mathrm{~N}$ DNA content is shown in the table (percentages standard deviations were calculated from three technical replicates).

F) Immunoblot analysis of control and MAD2 RNAi used in Figure 2E-F. Cells imaged for Figure $2 \mathrm{E}$ and Figure $2 \mathrm{~F}$ were lysed and expression of the indicated proteins was analysed by immunoblotting. A representative blot of the three independently performed experiments is shown. GAPDH levels were analysed to control for equal loading.

\section{Supplemental figure 3}

A) Immunoblot of input cells used for mixing experiment outlined in Figure 3A. Equal number of wild-type, APC8-mCherry and APC8-mCherry $\triangle A P C 7$ cells were mixed and seeded together. Lysate from the individual cell lines and the resulting mixed cell population (on the day of transfection of MAD2-targeting Crispr/Cas9 plasmids) were analysed for expression of indicated proteins with immunoblotting.

B) Immunoblot analysis of the APC8-mCherry MAD2-GFP cell line along with its parental cell lines with indicated antibodies.

C) Immunoblot analysis of MAD2 expression in the six clones retrieved from MAD2-GFP synthetic viability assay performed in combination with an APC16 targeting guide RNA. Immunoblot for GAPDH serves as loading control.

D) Confirmation of APC16 locus disruption in four $\triangle M A D 2-G F P \triangle A P C 16$ clones. The genomic APC16 locus surrounding the guide RNA target site was cloned from four $\triangle M A D 2-$ GFP $\triangle$ APC16 clonal cell lines and sequenced. The table lists the obtained sequences, beginning with the start codon of APC16 and depicting the PAM sequence adjacent to the guide RNA in bold. Compared to the wild-type APC16 locus, deleted base pairs are shown in boxes, inserted base pairs are highlighted with grey background. Note that all sequenced mutations cause disruption of the APC16 reading frame.

\section{Supplemental figure 4}

A) Analysis of DNA content in $\triangle A P C 7 \triangle M A D 2$ and $\triangle M A D 2-G F P \triangle A P C 16$ clonal cell lines cells. The cellular DNA from wild-type, APC8-mCherry, $\triangle$ APC7 $\triangle M A D 2$, APC8-mCherry MAD2-GFP and $\triangle M A D 2-G F P \triangle A P C 16$ clonal cell lines was stained with propidium iodide and analysed by FACS. The table shows the percentage of cells with the respective $(2 \mathrm{~N}, 2 \mathrm{~N}-4 \mathrm{~N}, 4 \mathrm{~N}$ and $>4$ N) DNA content.

B) Representative images of chromosome segregation errors summarized in Figure 4C. 
bioRxiv preprint doi: https://doi.org/10.1101/222422; this version posted November 20, 2017. The copyright holder for this preprint (which was not certified by peer review) is the author/funder, who has granted bioRxiv a license to display the preprint in perpetuity. It is made available under aCC-BY 4.0 International license.

Figure 1

A

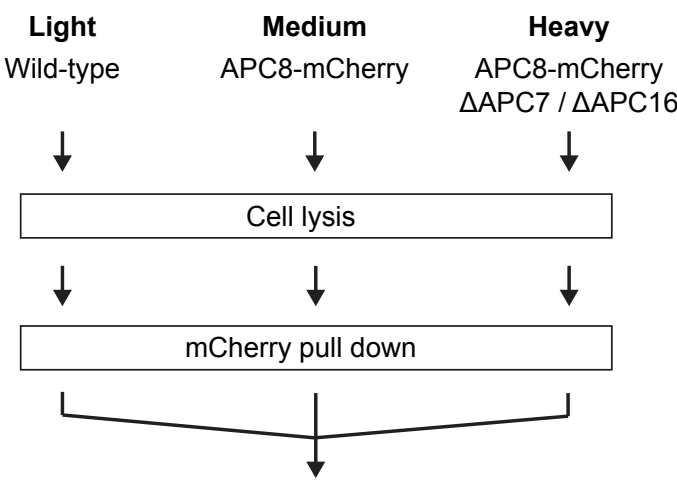

In-gel protein digestion

\section{LC-MS/MS}

B

\begin{tabular}{cccc}
\cline { 2 - 4 } APC subunits & SILAC ratio \\
\hline APC1 & 25.18 & 26.20 & 1.06 \\
\hline APC2 & 25.60 & 25.29 & 1.00 \\
\hline APC3 & 17.53 & 20.03 & 1.12 \\
\hline APC4 & 19.98 & 21.46 & 1.06 \\
\hline APC5 & 19.34 & 21.23 & 1.07 \\
\hline APC6 & 19.58 & 21.37 & 1.08 \\
\hline APC7 & 40.15 & n.d. & n.d. \\
\hline APC8 & 16.65 & 20.91 & 1.25 \\
\hline APC10 & 22.13 & 24.07 & 1.07 \\
\hline APC12 & 31.06 & 32.59 & 1.08 \\
\hline APC13 & 23.05 & 25.71 & 1.15 \\
\hline APC15 & 23.40 & 24.69 & 1.07 \\
\hline APC16 & 19.04 & 16.50 & 0.84 \\
\hline
\end{tabular}

C

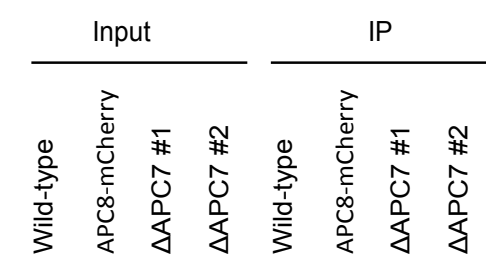

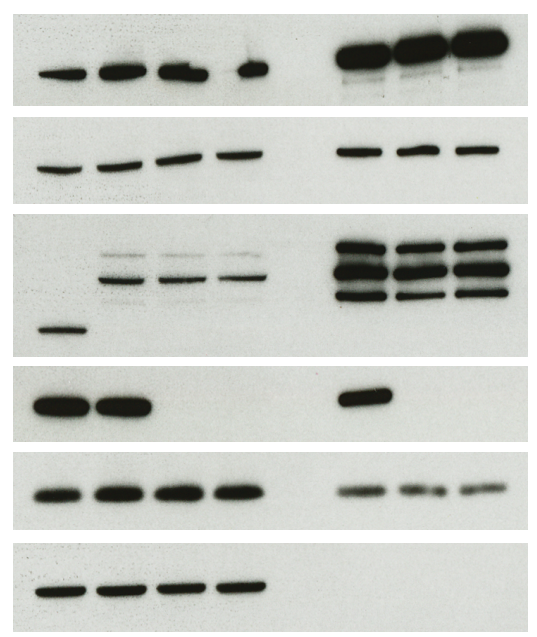

D

\begin{tabular}{cccc}
\cline { 2 - 4 } APC subunits & SILAC ratio \\
\hline APC1 & 20.71 & 26.39 & 1.27 \\
\hline APC2 & 22.39 & 22.88 & 1.01 \\
\hline APC3 & 21.58 & 18.00 & 0.83 \\
\hline APC4 & 20.15 & 24.26 & 1.17 \\
\hline APC5 & 19.42 & 22.88 & 1.14 \\
\hline APC6 & 21.84 & 20.45 & 0.90 \\
\hline APC7 & 14.21 & 0.14 & 0.01 \\
\hline APC8 & 14.64 & 24.24 & 1.63 \\
\hline APC10 & 23.30 & 20.99 & 0.79 \\
\hline APC12 & 26.64 & 21.55 & 0.84 \\
\hline APC13 & 14.60 & 21.04 & 1.40 \\
\hline APC15 & 16.05 & 29.51 & 1.91 \\
\hline APC16 & 34.43 & n.d. & n.d. \\
\hline
\end{tabular}

E

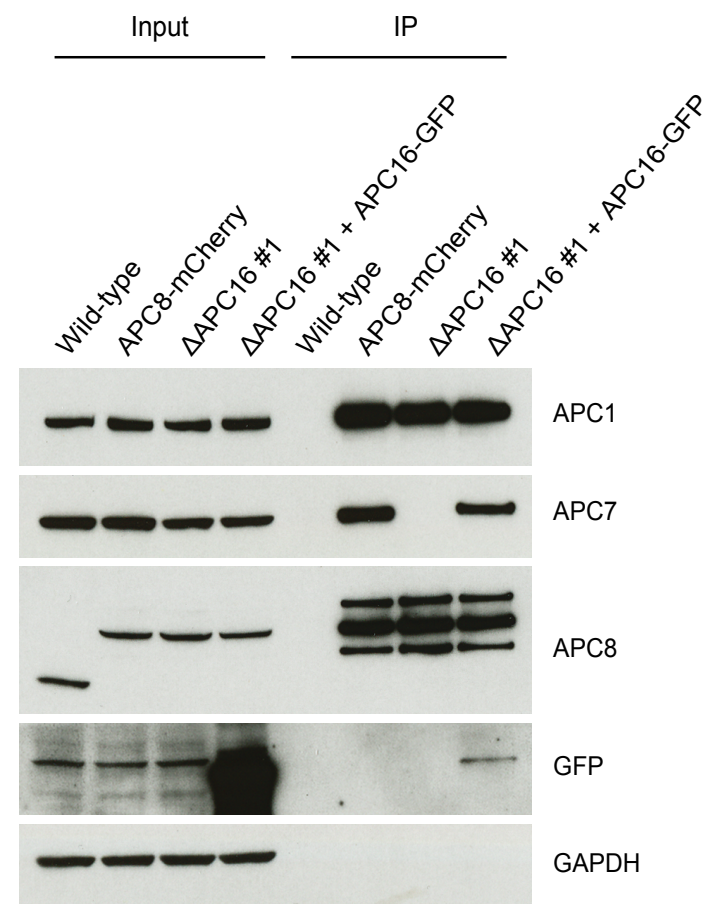


bioRxiv preprint doi: https://doi.org/10.1101/222422; this version posted November 20, 2017. The copyright holder for this preprint (which

was not certified by peer review) is the author/funder, who has granted bioRxiv a license to display the preprint in perpetuity. It is made available under aCC-BY 4.0 International license.

Figure 2

A

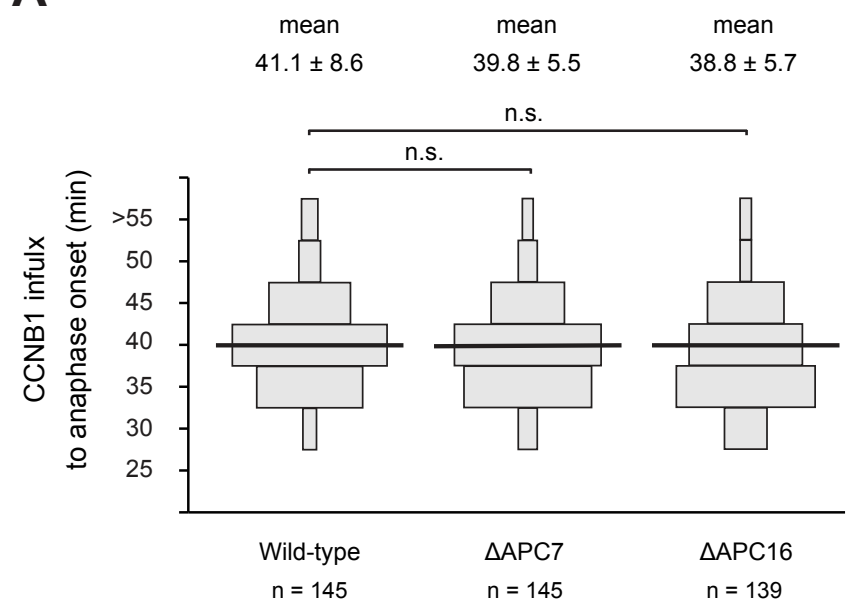

C

\begin{tabular}{|c|c|c|c|c|}
\hline \multicolumn{5}{|c|}{$\mathrm{APC} / \mathrm{C}$} \\
\hline & & $\begin{array}{c}\mathbf{M} / \mathbf{L} \\
\text { untreated / - }\end{array}$ & $\begin{array}{c}\mathbf{H} / \mathbf{L} \\
\operatorname{noc} /-\end{array}$ & $\begin{array}{c}\mathbf{H} / \mathbf{M} \\
\text { noc / untreated }\end{array}$ \\
\hline \multirow{13}{*}{ 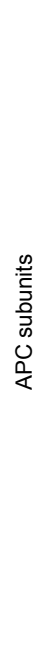 } & APC1 & 39.99 & 26.44 & 0.68 \\
\hline & APC2 & 38.03 & 32.36 & 0.89 \\
\hline & APC3 & 25.41 & 22.43 & 0.91 \\
\hline & APC4 & 28.16 & 19.73 & 0.71 \\
\hline & APC5 & 26.52 & 19.30 & 0.71 \\
\hline & APC6 & 22.24 & 20.96 & 0.92 \\
\hline & APC7 & 22.78 & 22.92 & 1.00 \\
\hline & APC8 & 26.66 & 19.31 & 0.70 \\
\hline & APC10 & 22.53 & 22.21 & 0.93 \\
\hline & APC12 & 35.95 & 35.32 & 0.99 \\
\hline & APC13 & 40.62 & 28.47 & 0.72 \\
\hline & APC15 & 38.91 & 27.23 & 0.69 \\
\hline & APC16 & 23.19 & 22.48 & 0.97 \\
\hline \multirow{4}{*}{ 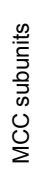 } & BUB3 & 7.68 & 49.50 & 6.52 \\
\hline & BUBR1 & 5.91 & 38.42 & 6.63 \\
\hline & $\mathrm{CDC} 20$ & 9.95 & 58.96 & 5.79 \\
\hline & MAD2 & 4.31 & 30.06 & 6.26 \\
\hline
\end{tabular}

E

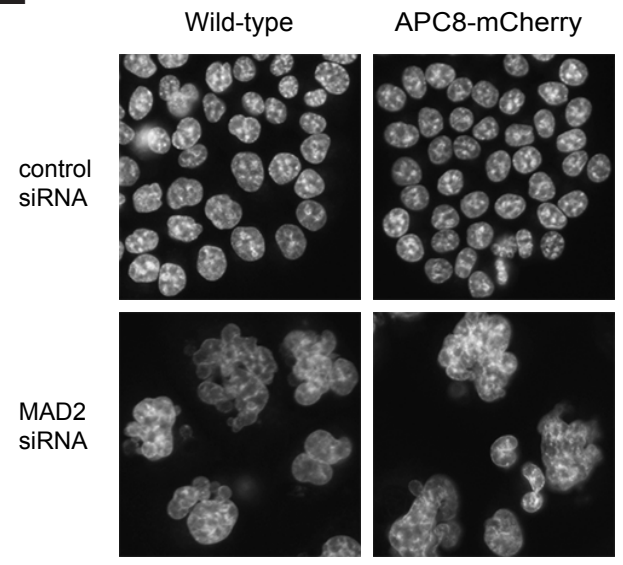

B

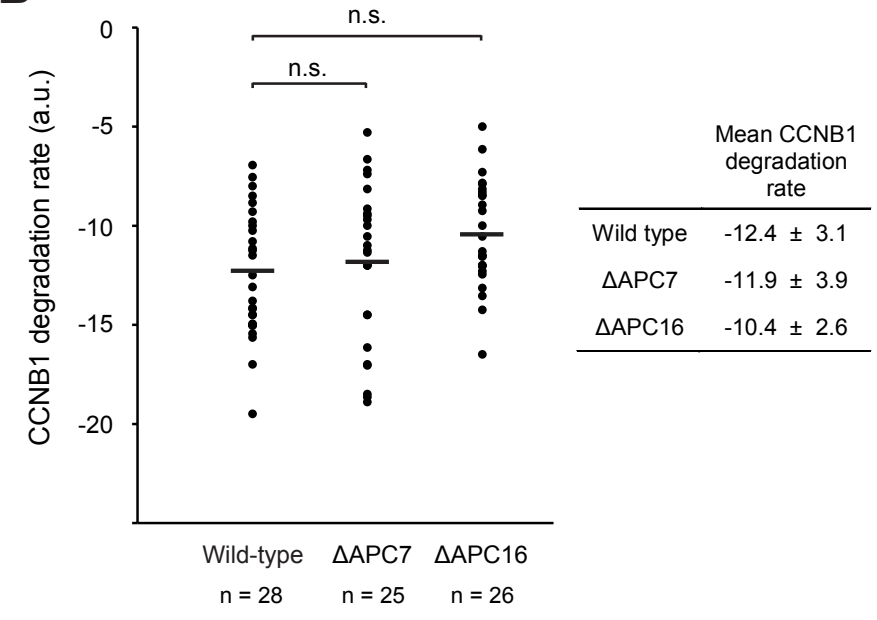

D

\begin{tabular}{|c|c|c|c|c|}
\hline & \multicolumn{3}{|c|}{$A P C / C^{\triangle A P C 7}$} \\
\hline & & $\begin{array}{c}\mathbf{M} / \mathbf{L} \\
\text { untreated / - }\end{array}$ & $\begin{array}{c}\text { H/L } \\
\text { noc } /-\end{array}$ & $\begin{array}{c}\mathbf{H} / \mathbf{M} \\
\text { noc / untreated }\end{array}$ \\
\hline \multirow{12}{*}{$\begin{array}{l}0.0 \\
: 0 \\
5 \\
0 \\
0 \\
0 \\
0 \\
\frac{0}{4}\end{array}$} & APC1 & 30.53 & 23.25 & 0.78 \\
\hline & APC2 & 29.64 & 26.09 & 0.89 \\
\hline & APC3 & 22.72 & 19.90 & 0.89 \\
\hline & APC4 & 24.34 & 19.40 & 0.81 \\
\hline & APC5 & 22.83 & 19.08 & 0.82 \\
\hline & APC6 & 20.95 & 17.74 & 0.85 \\
\hline & APC8 & 24.02 & 22.29 & 0.96 \\
\hline & APC10 & 30.79 & 29.21 & 0.90 \\
\hline & APC12 & 28.92 & 25.02 & 0.89 \\
\hline & APC13 & 25.24 & 24.38 & 0.96 \\
\hline & APC15 & 27.83 & 22.10 & 0.79 \\
\hline & APC16 & 23.28 & 19.67 & 0.87 \\
\hline \multirow{4}{*}{ 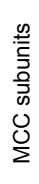 } & BUB3 & 3.02 & 42.49 & 14.26 \\
\hline & BUBR1 & 2.71 & 42.19 & 15.34 \\
\hline & CDC20 & 4.29 & 48.85 & 12.07 \\
\hline & MAD2 & 3.14 & 41.07 & 13.56 \\
\hline
\end{tabular}

F

control siRNA $\square$ MAD2 siRNA

$\triangle \mathrm{APC16}$
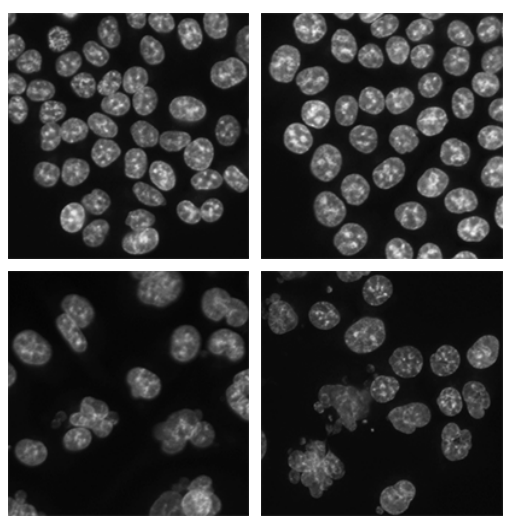

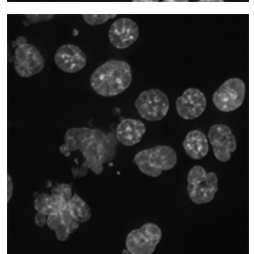


bioRxiv preprint doi: https://doi.org/10.1101/222422; this version posted November 20, 2017. The copyright holder for this preprint (which was not certified by peer review) is the author/funder, who has granted bioRxiv a license to display the preprint in perpetuity. It is made available under aCC-BY 4.0 International license.

Figure 3

A

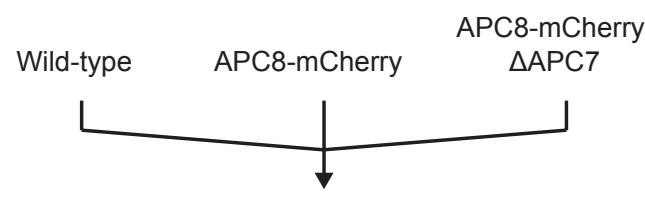

$1: 1: 1$

mixed cell population

MAD2 deletion cassette

clonal $\triangle \mathrm{MAD} 2$ cell lines

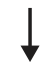

determine parental cell line
B

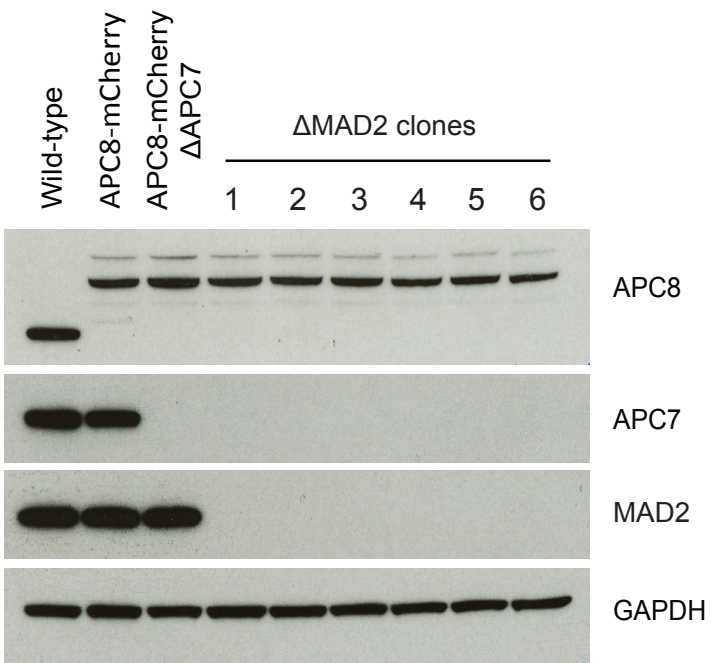

D
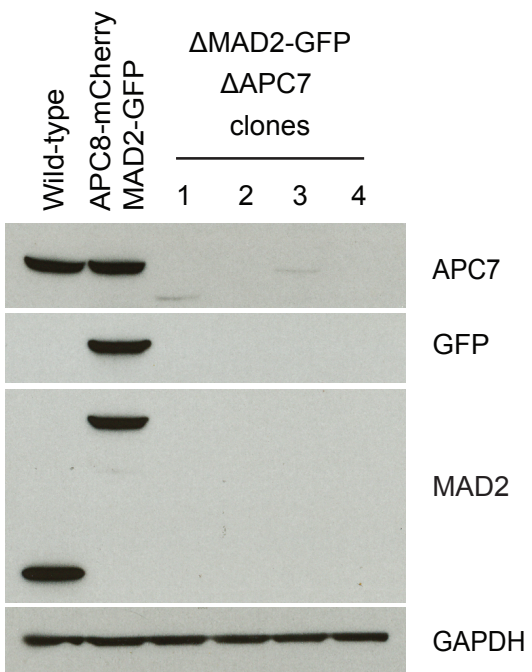

E

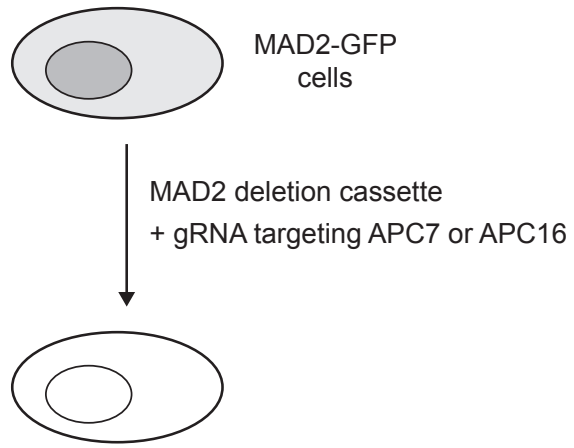

visual selection for loss of GFP

Wild-type

noc $(-)$

noc $(+)$

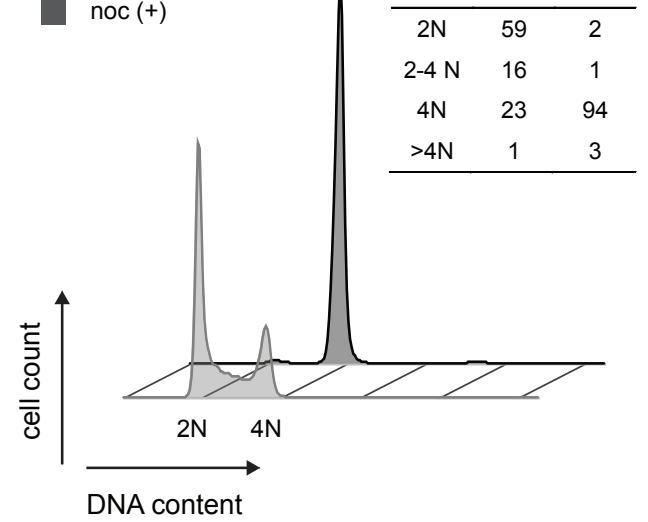

$\triangle \mathrm{APC} 7 \triangle \mathrm{MAD} 2$

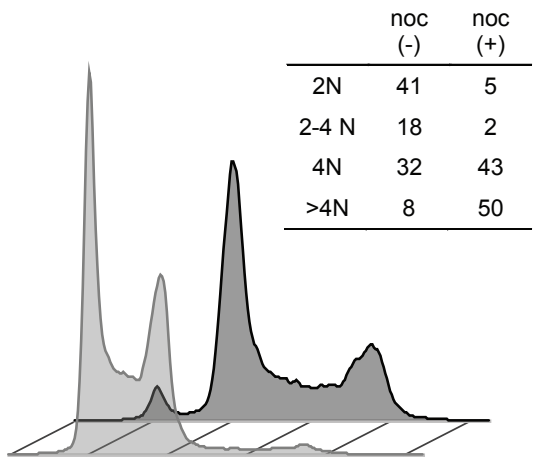

$2 \mathrm{~N} \quad 4 \mathrm{~N}$

$\triangle M A D 2-G F P \triangle A P C 16$

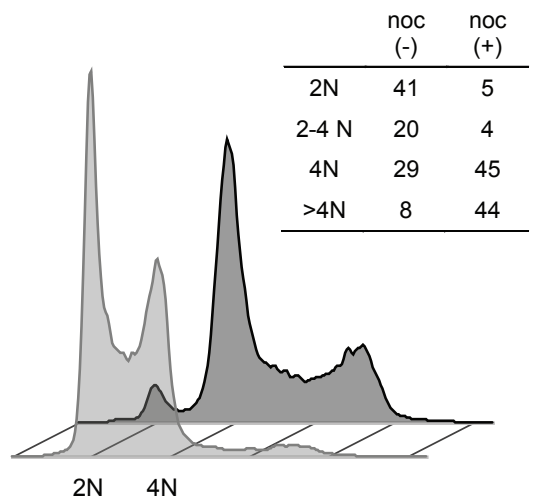




\section{A}

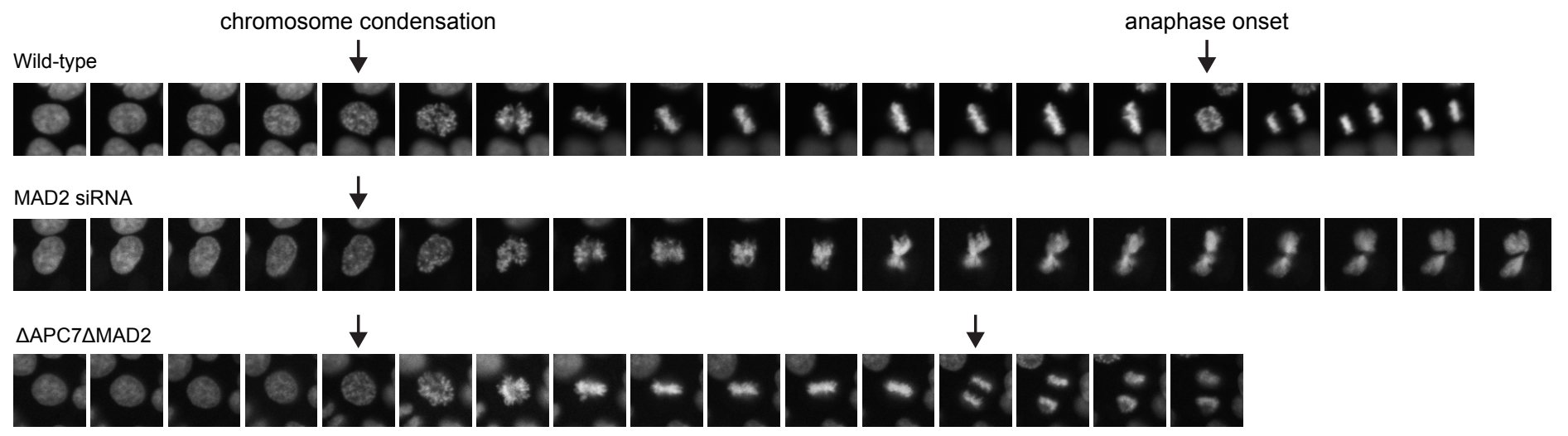

B

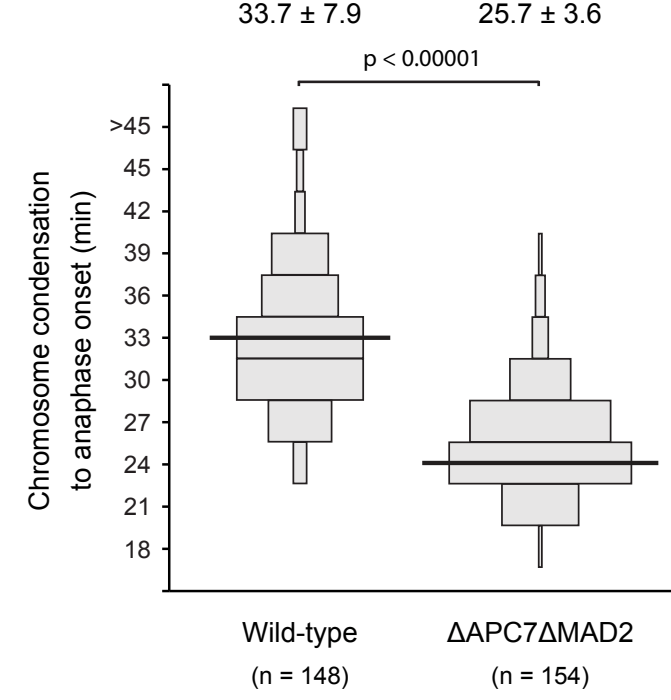

D

Wild-type

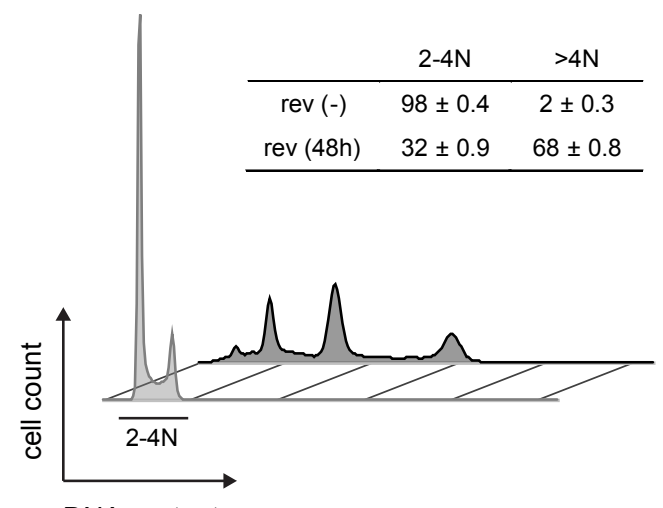

C

\begin{tabular}{cccc} 
& Wild type & $\begin{array}{c}\Delta \text { APC7 } \\
\Delta \text { MAD2 }\end{array}$ & $\begin{array}{c}\text { Wild type + } \\
\text { MAD2 RNAi }\end{array}$ \\
\hline Normal mitosis (number of cells / \% cells) & $148 / 100 \%$ & $140 / 89 \%$ & $18 / 13 \%$ \\
\hline Abberant mitosis without metaphase plate: & & & 39 \\
without chromosome separation & 0 & 2 & 76 \\
with chromosome separation & 0 & 10 & 2 \\
\hline Abberant mitosis with metaphase plate formation: & 0 & 1 & 0 \\
chromosome bridge after anaphase onset & 0 & 1 & 0 \\
\hline unaligned chromosome before anaphase onset & 0 & $18 / 11 \%$ & $117 / 87 \%$ \\
\hline uneven cell division & $0 / 0 \%$ & & \\
\hline Total errors (number of cells / \% cells) & & & \\
\hline
\end{tabular}

$\triangle \mathrm{APC7} \triangle \mathrm{MAD} 2$

$\triangle M A D 2-G F P \triangle A P C 16$

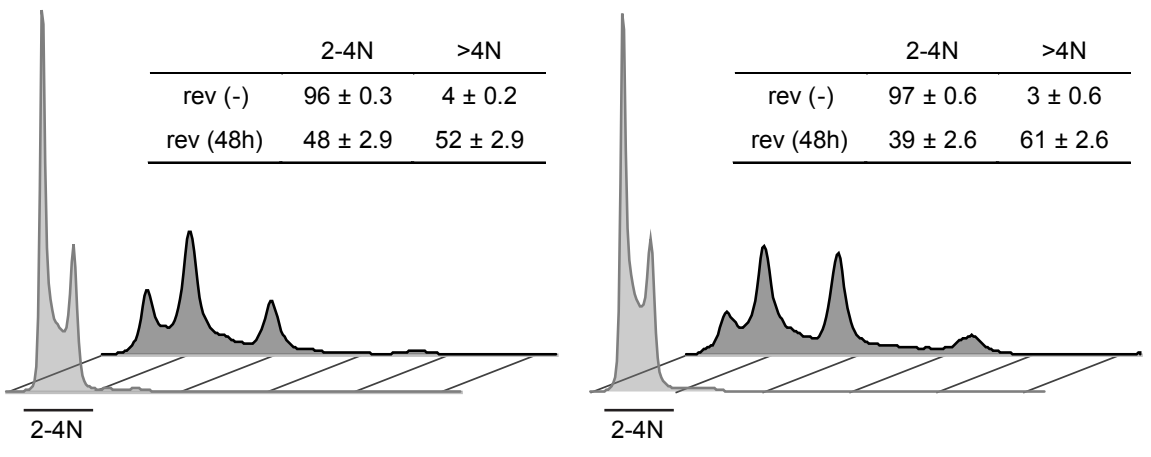

DNA content 
bioRxiv preprint doi: https://doi.org/10.1101/222422; this version posted November 20, 2017. The copyright holder for this preprint (which was not certified by peer review) is the author/funder, who has granted bioRxiv a license to display the preprint in perpetuity. It is made available under aCC-BY 4.0 International license.

\section{Supplemental figure 1}

A

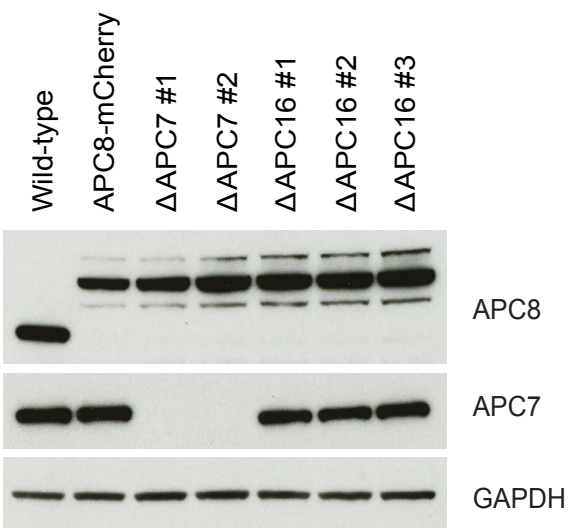

B

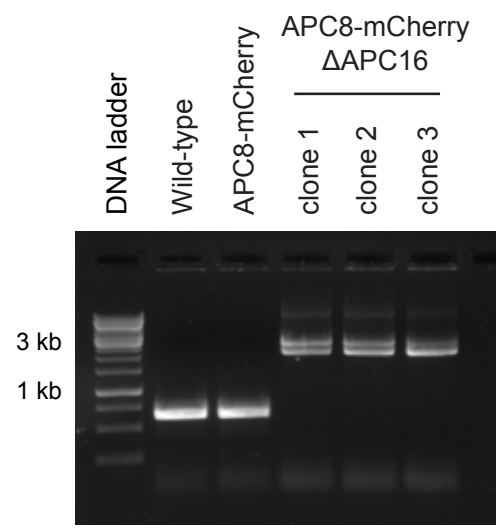

C

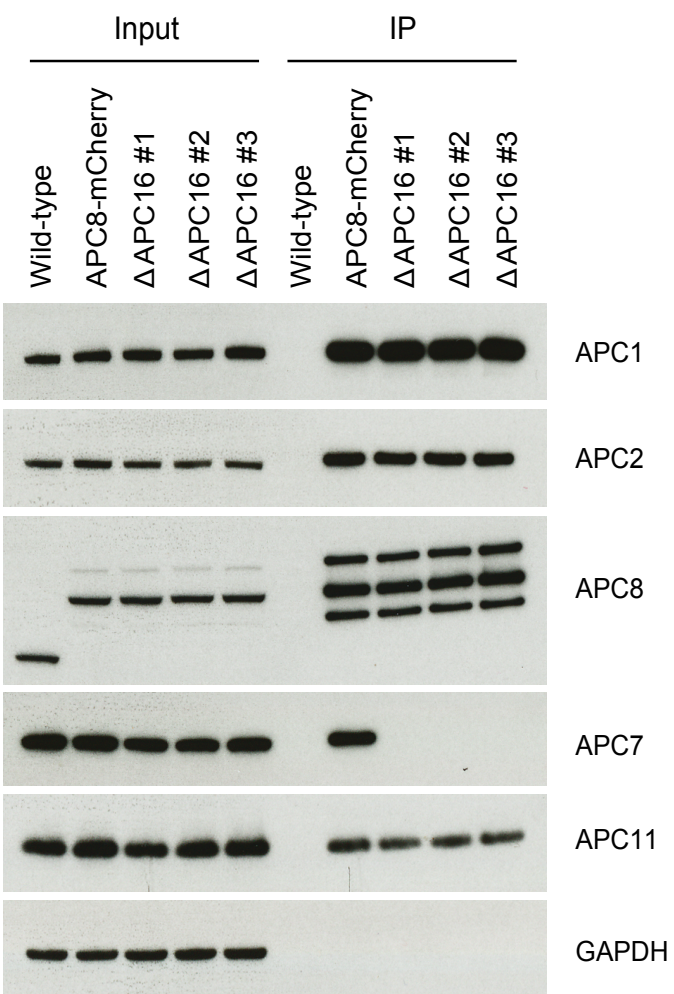




\section{Supplemental figure 2}

A

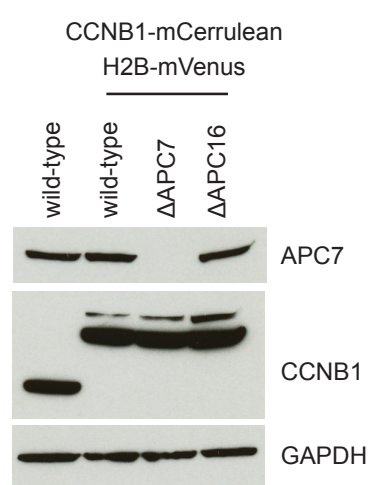

B

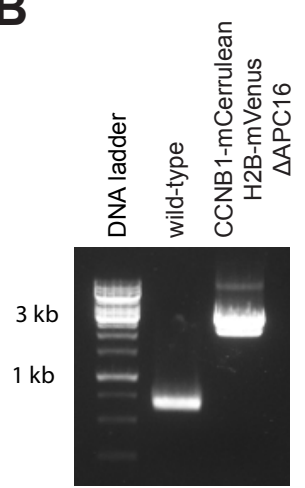

$\mathbf{F}$

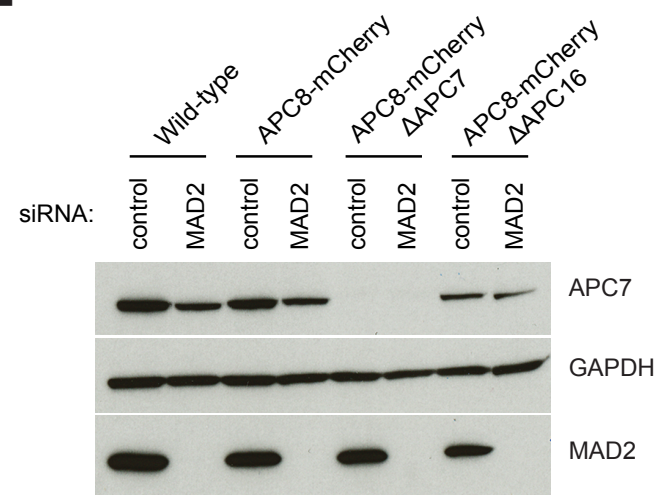

C

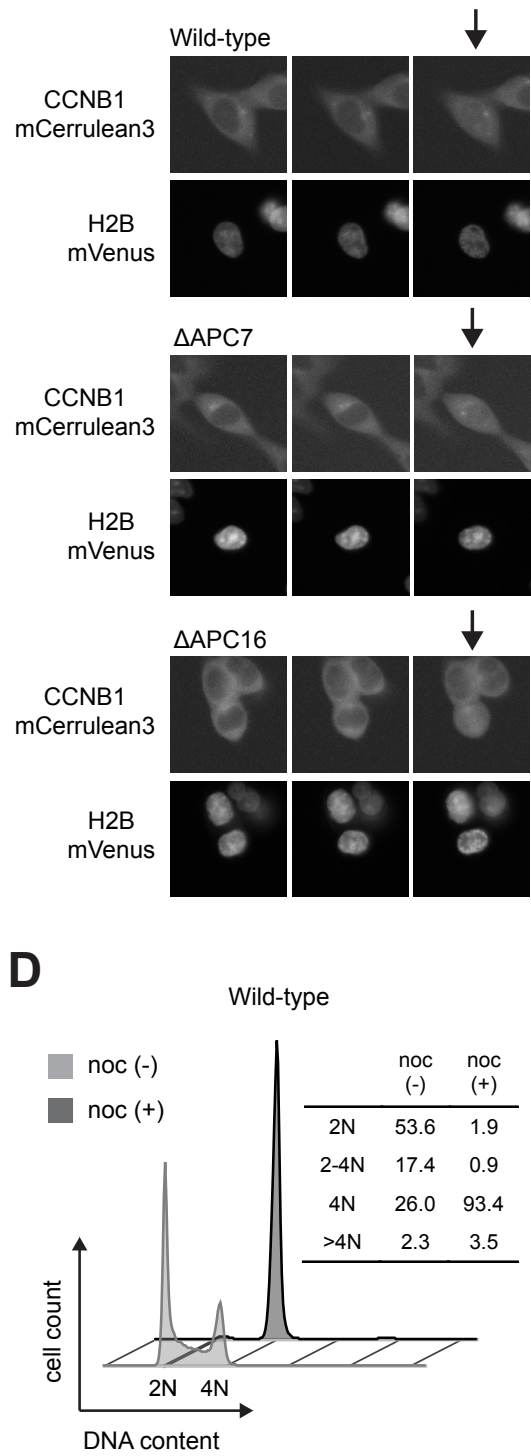

CCNB1 influx
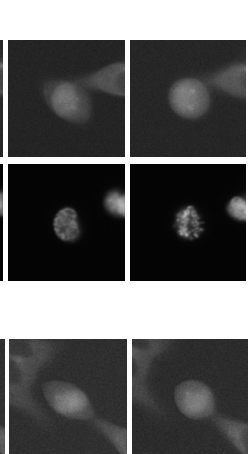
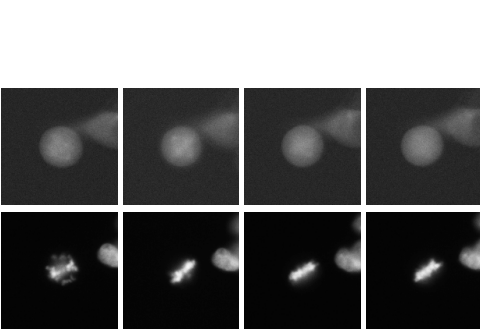

anaphase onset

$\mathbf{E}$

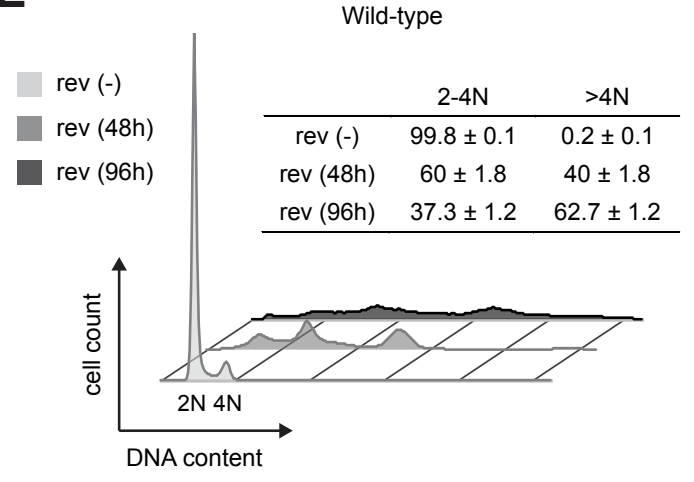

$\triangle \mathrm{APC7}$

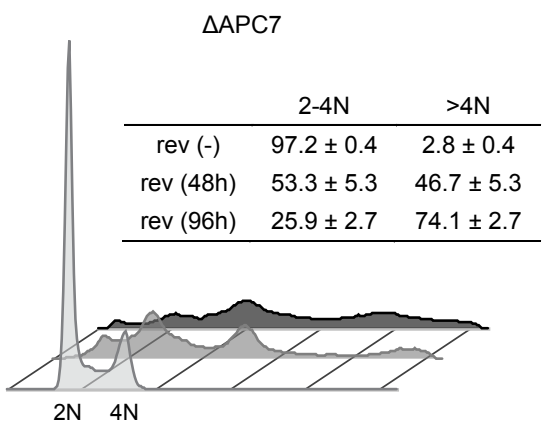

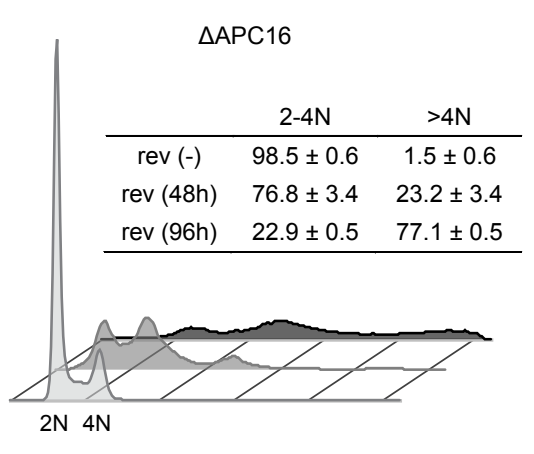


bioRxiv preprint doi: https://doi.org/10.1101/222422; this version posted November 20, 2017. The copyright holder for this preprint (which was not certified by peer review) is the author/funder, who has granted bioRxiv a license to display the preprint in perpetuity. It is made available under aCC-BY 4.0 International license.

Supplemental figure 3

A

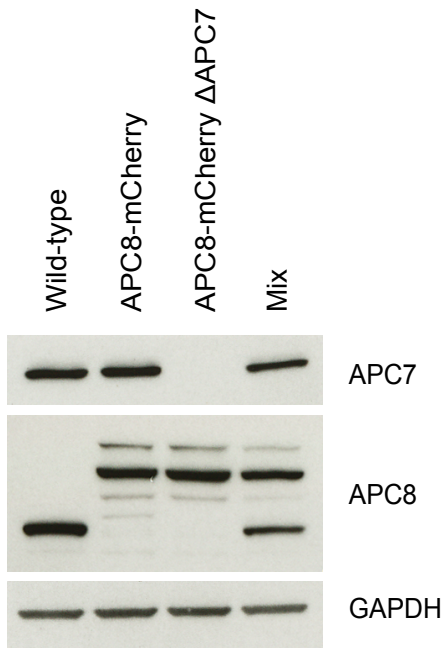

B

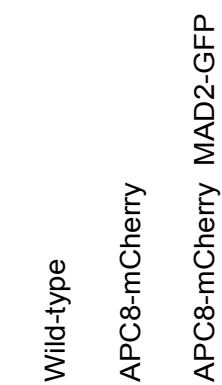

C

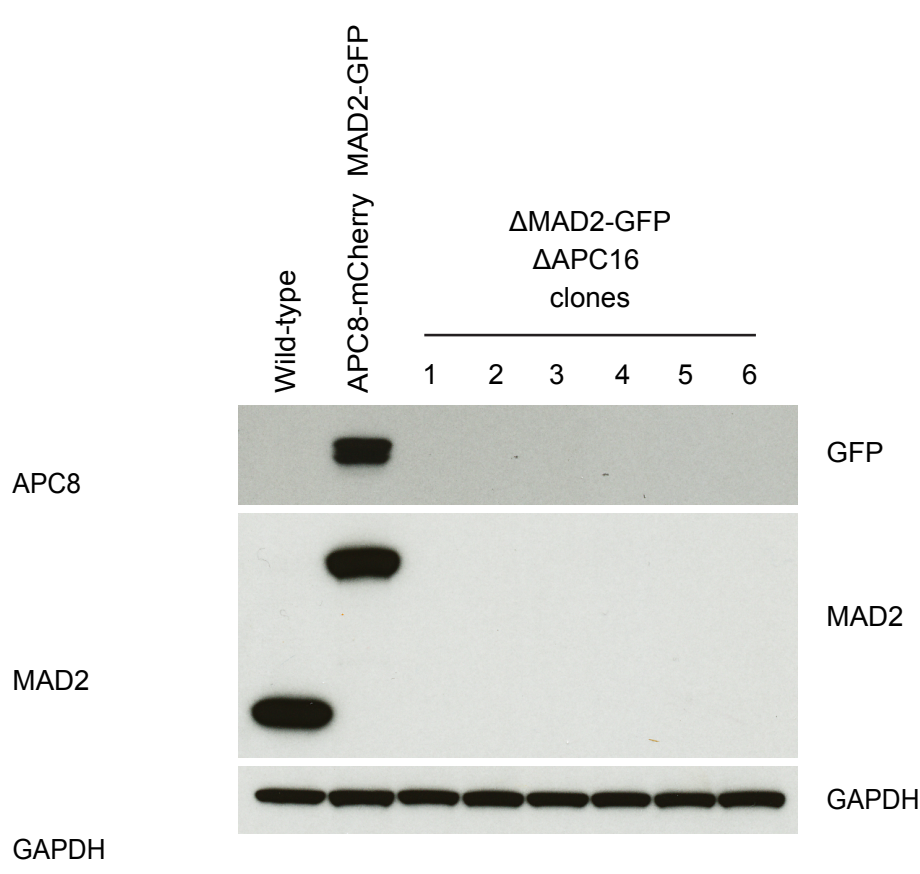

D

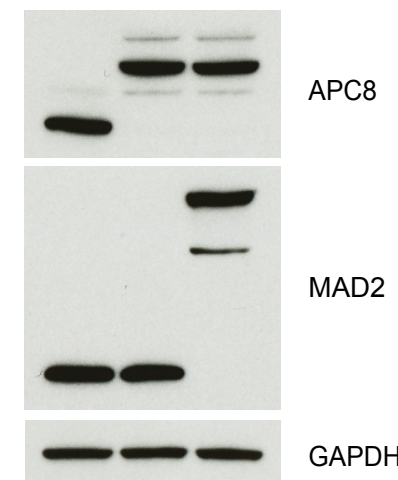

APC8-mCherry $\triangle$ Mad2-GFP $\triangle \mathrm{APC} 16$ clone \#1

APC8mCherry $\triangle$ Mad2-GFP $\triangle \mathrm{APC} 16$ clone \#2

APC8-mCherry $\triangle$ Mad2-EGFP $\triangle \mathrm{APC} 16$ clone \#3

APC8-mCherry
$\triangle$ Mad2-GFP
$\triangle \mathrm{APC} 16$
clone \#4

Allele 1:

ATGGCTGCTTCATCATCATCCTCCTCAGCTGGTGGGGTCAGTGGAAGTTCTGTCACTGGATCTGGTTTCAGT GTCTCAGACCTTGCCCCACCACGGAAAGCCCTTTTCACCTACCCCAAAGGAGCTGGAGAGATGTTAGAAG

Allele 2:

ATGGCTGCTTCATCATCATCCTCCTCAGCTGGTGGGGTCAGTGGAAGTTCTGTCACTGGATCTGGTTTCAGT GTCTCAGACCTTGCCCCACCACGGAAAG CCCTTTTCACCTACCCCAAAGGAGCTGGAGAGATGTTAGAAG

Allele 1:

ATGGCTGCTTCATCATCATCCTCCTCAGCTGGTGGGGTCAGTGGAAGTTCTGTCACTGGATCTGGTTTCAGT GTCTCAGACCTTGCCCCACCACGGAAAGCCCTTTTCACCTACCCCAAAGGAGCTGGAGAGATGTTAGAAG Allele 2:

ATGGCTGCTTCATCATCATCCTCCTCAGCTGGTGGGGTCAGTGGAAGTTCTGTCACTGGATCTGGTTTCAGT GTCTCAGACCTTGCCCCACCACGGAAAGCCCTTTTCACCTACCCCAAAGGAGCTGGAGAGATGTTAGAAG

Allele 1:

ATGGCTGCTTCATCATCATCCTCCTCAGCTGGTGGGGTCAGTGGAAGTTCTGTCACTGGATCTGGTTTCAGT GTCTCAGACCTTGCCCCACCACGGAAAGCCCTTTTCACCTACCCCAAAGGAGCTGGAGAGATGTTAGAAG Allele 2:

ATGGCTGCTTCATCATCATCCTCCTCAGCTGGTGGGGTCAGTGGAAGTTCTGTCACTGGATCTGGTTTCAGTGT CTCAGACCTTGCCCCACCACGGAAAGCCCTTTTCACCTACCCCAAAGGAGCTGGAGAGATGTTAGAAG

Allele 1:

ATGGCTGCTTCATCATCATCCTCCTCAGCTGGTGGGGTCAGTGGAAGTTCTGTCACTGGATCTGGTTTCAGTGT CTCAGACCTTGCCCCACCACGGAAAGCCCTTTTCACCTACCCCAAAGGAGCTGGAGAGATGTTAGAAG Allele 2:

ATGGCTGCTTCATCATCATCCTCCTCAGCTGGTGGGGTCAGTGGAAGTTCTGTCACTGGATCTGGTTTCAGTGT CTCAGACCTTGCCCCACCACGGAAAGCCCTTTTCACCTACCCAGTATAATCTGCAGTCAATATTTCTGCGAAAGC TTACTACTTCAAAGCCTTAAAAAGTGCATACTTTGGTCCAGCAAGTACCATTCCAATAATTTTTTCTGAGAAAATAAT CAAGGATACCAAAGGAGCTGGAGAGATGTTAGAAG 
bioRxiv preprint doi: https://doi.org/10.1101/222422; this version posted November 20, 2017. The copyright holder for this preprint (which

was not certified by peer review) is the author/funder, who has granted bioRxiv a license to display the preprint in perpetuity. It is made available under aCC-BY 4.0 International license.

Supplemental figure 4

A

Wild-type

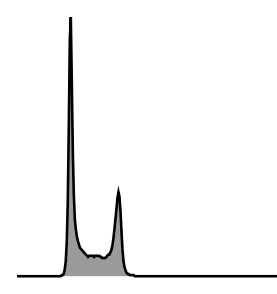

$2 \mathrm{~N} 4 \mathrm{~N}$
APC8-mCherry

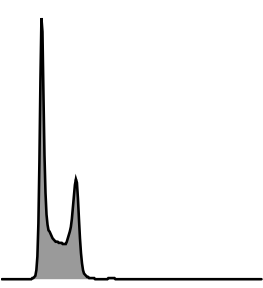

APC8-mCherry MAD2-GFP

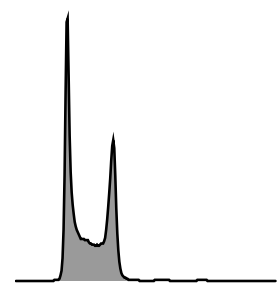

$\triangle \mathrm{APC7} \triangle \mathrm{MAD} 2 \# 1$

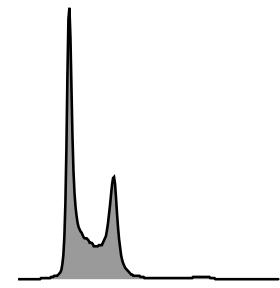

$\triangle A P C 16 \triangle M A D 2 \# 1$

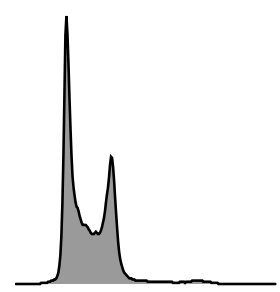

$\triangle \mathrm{APC7} \triangle \mathrm{MAD} 2 \# 2$

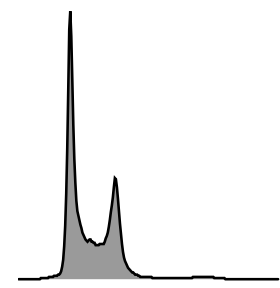

$\triangle A P C 16 \triangle M A D 2 \# 2$

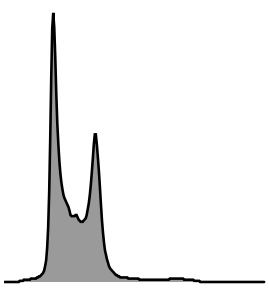

$\triangle \mathrm{APC7} \triangle \mathrm{MAD} 2 \# 3$

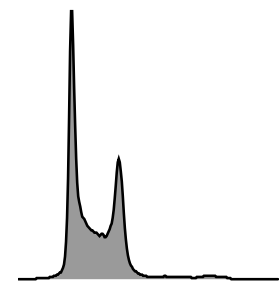

$\triangle \mathrm{APC} 16 \triangle \mathrm{MAD} 2 \# 3$

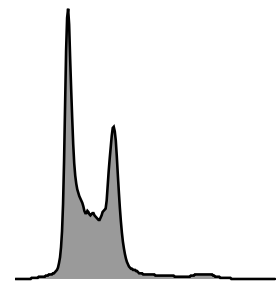

$\triangle \mathrm{APC7} \triangle \mathrm{MAD} 2 \# 4$

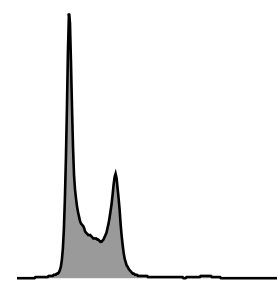

$\triangle \mathrm{APC} 16 \triangle \mathrm{MAD} 2 \# 4$

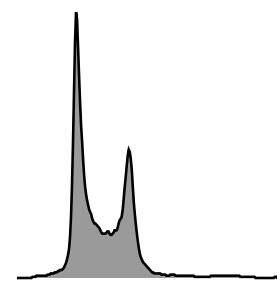

DNA content

\begin{tabular}{ccccc} 
& $2 \mathrm{~N}$ & $2-4 \mathrm{~N}$ & $4 \mathrm{~N}$ & $>4 \mathrm{~N}$ \\
\hline Wild-type & $35 \pm 2$ & $43 \pm 2$ & $18 \pm 1$ & $2 \pm 0.3$ \\
APC8-mCherry & $33 \pm 1$ & $44 \pm 0.1$ & $19 \pm 1$ & $2 \pm 0.4$ \\
$\triangle$ APC7DMAD2 (clones 1-4) & $30 \pm 2$ & $42 \pm 2$ & $18 \pm 0.4$ & $7 \pm 1$ \\
APC8-mCherry MAD2-GFP & $27 \pm 1$ & $49 \pm 1$ & $20 \pm 1$ & $3 \pm 1$ \\
$\triangle$ MAD2-GFP $\triangle A P C 16$ (clones 1-4) & $26 \pm 2$ & $46 \pm 1$ & $18 \pm 1$ & $7 \pm 1$ \\
\hline
\end{tabular}

B

No chromosome segregation (MAD2 RNAi)
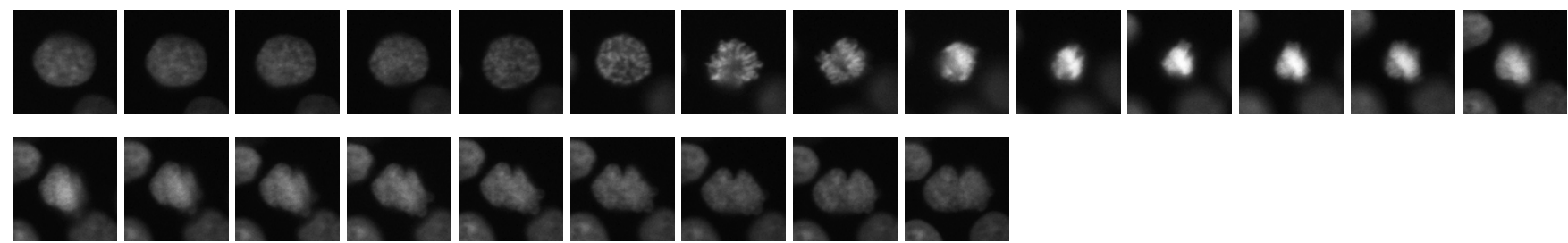

Chromosome brigde ( $\triangle \mathrm{APC} 7 \triangle \mathrm{MAD} 2)$
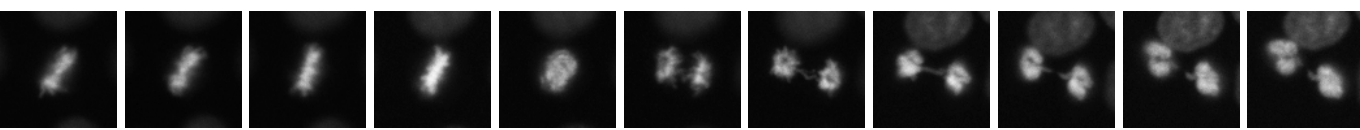

Unaligned chromosome before anaphase onset ( $\triangle \mathrm{APC} 7 \mathrm{MAD2}$ )
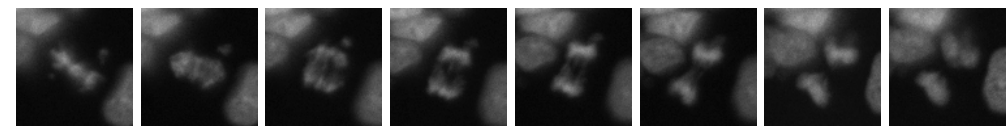

Uneven cell division ( $\triangle \mathrm{APC} 7 \triangle \mathrm{MAD} 2)$
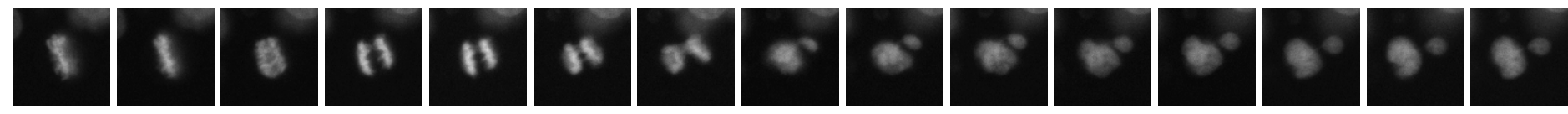